$$
\text { RN-TM-0592 }
$$

\title{
AN EXPERIMENTAL STUDY OF THE NOISE FIELD RESULTING FROM GROUND TESTING A NUCLEAR ROCKET ENGINE
}
NERVA Program
Contract SNP-1

December 1969
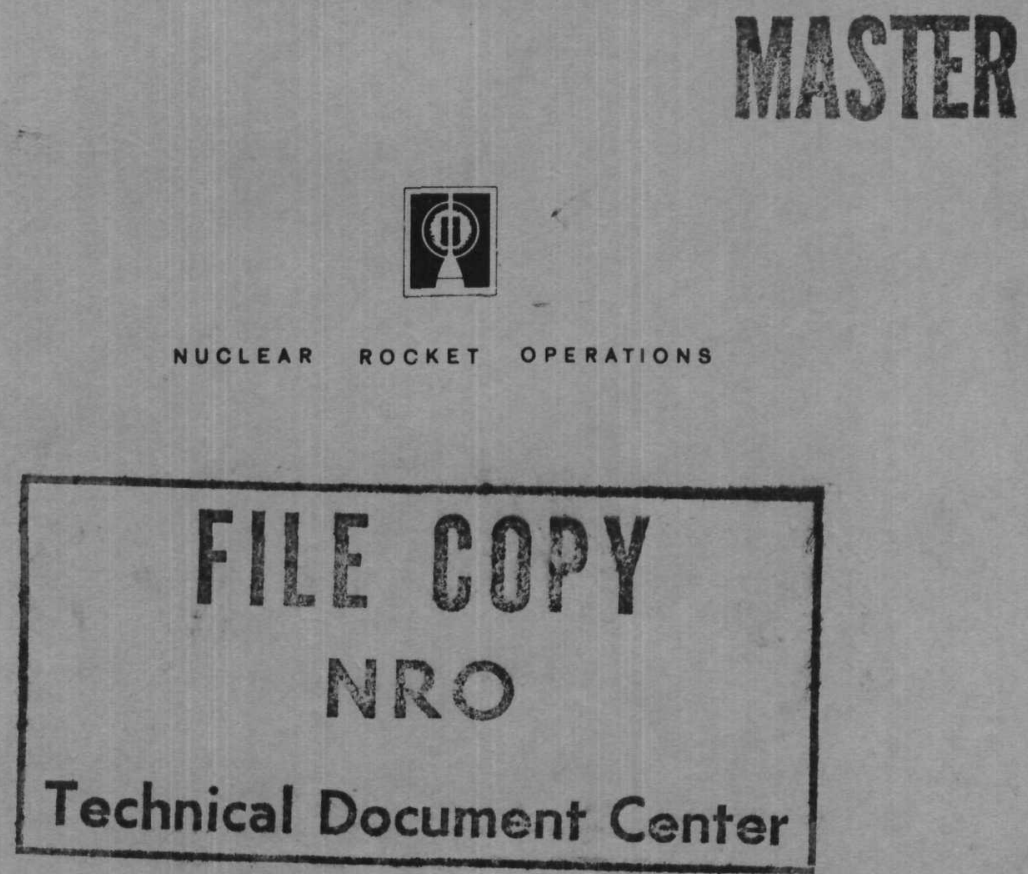

TECHNICAL DOCUMENT CENTER DISTRIBUTION OF THIS DOCUMENT UNLIMITED Nuclear Rocket Operations 


\section{DISCLAIMER}

This report was prepared as an account of work sponsored by an agency of the United States Government. Neither the United States Government nor any agency Thereof, nor any of their employees, makes any warranty, express or implied, or assumes any legal liability or responsibility for the accuracy, completeness, or usefulness of any information, apparatus, product, or process disclosed, or represents that its use would not infringe privately owned rights. Reference herein to any specific commercial product, process, or service by trade name, trademark, manufacturer, or otherwise does not necessarily constitute or imply its endorsement, recommendation, or favoring by the United States Government or any agency thereof. The views and opinions of authors expressed herein do not necessarily state or reflect those of the United States Government or any agency thereof. 


\section{DISCLAIMER}

Portions of this document may be illegible in electronic image products. Images are produced from the best available original document. 
AEROJET

GENERAL TIRE

GENERAL

RN-TM-0592
NOTICE

This report was prepared as an account of work sponsored by the United States Government. Neither the United States nor the United States Energy Research and Development Administration, nor any of their employees, nor any of their contractors, subcontractors, or their employees, makes any warranty, express or implied, or assumes any legal liability or responsibility for the accuracy, completeness or usefulness of any information, apparatus, product or process disclosed, or represents that its use would not infringe privately owned rights.

\section{AN EXPERIMENTAL STUDY OF THE}

\section{NOISE FIELD RESULTING FROM GROUND TESTING A}

\section{NUCLEAR ROCKET ENGINE}

NERVA Program Contract SNP-1
NUCLEAR ROCKET OPERATIONS
December 1969

\section{CLASSIFICATION CATEGORY}

\section{UNCLASSIFIED}

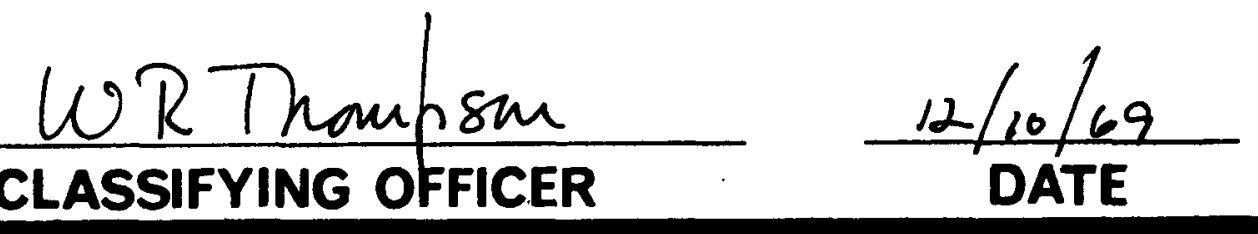

\section{AER OJET - GENERAL CORPORATION \\ A SUBSIDIARY OF The GENERAL TIRE L RUBEER COMPANY}


NRO TECHNICAL MEYORANDUY

RN-TM-0592

AN EXPERIMENTAL STUDY OF THE

NOISE FIELD RESULTIKG FROK GROUND TESTING A

NUCLEAR ROCKET ERGIKE

20 October 1969

PREPARED BY:

R. S Taisall

R. S. Falrall

$\frac{L}{\text { W. R. Thompson }}$
APPROVED BY:
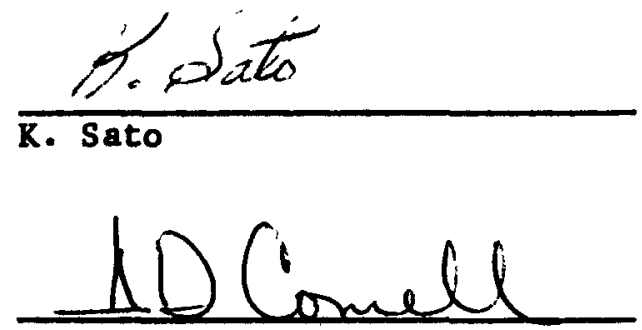

A. D. Cornel1
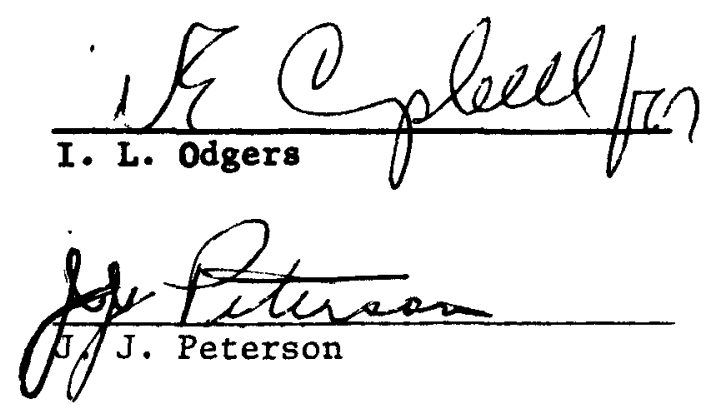


\section{ABSTRACT}

The experimental engine cold flow (XECF) tests were conducted in April 1968 in Engine Test Stand No. 1 (ETS-1) at the Nuclear Rocket Development Station (NRDS) in Nevada. Posttest inspection of ETS-1 showed evidence of damage that was caused by acoustic forces. Because the duct effluent from XECF tests had relatively low kinetic energy, it was apparent that the jet noise anticipated during later high-power engine tests could reach destructive levels.

To determine the magnitude and extent of the noise field resulting from ground tests of the rocket engine, Aerojet-General Corporation began a comprehensive investigation to identify the factors necessary to define the acoustics. The investigation was divided into four steps: (1) analytical predictions of the acoustic environment, (2) scale-model tests to clarify the empirical factors required for analysis, (3) improvement of the facility components as required, and (4) acoustic measurements of the sound pressures during power tests (up to and including the full-power test and comparison of measured data with predictions). This report describes the fourth step in detail and summarizes the entire investigation. The experimental information, theoretical results, and full-scale test data are expected to be of value to other investigators in the field of acoustics.

The ground-test facility for the nuclear rocket requires an engine test compartment (ETC) that will enclose the engine and a nuclear exhaust system (NES) to convey the heated hydrogen propellant (primary fluid) away from the engine and ETS-1. Typically, the ETC is purged with a small amount of nitrogen gas. Further purging and a low nozzle back pressure are provided by introducing a large flow of high-temperature steam (secondary fluid) into the NES. The resulting mixture of gases burns along the surface of the plume at a rate that is controlled by the diffusion of ambient oxygen into the hydrogen-rich jet. 
The results of 16 tests are reported. The gases used were principally hydrogen, steam, and nitrogen. Mixtures of these gases, at various velocities and temperatures, were expelled from the duct that terminated in a 45-degree elbow to give an upward direction to the gas jet. Four external soundmeasuring microphones were used in the study; one was in the far field $400 \mathrm{ft}$ from the source, and three were in the near field at critical points on the sheet metal portion of ETS-1. All acoustic data were processed for spectral evaluation. There is a low frequency contribution that appears to result from the combustion process. Jet conversion efficiency, limits of combustion, and frequency-spectra results are reported. Oscillatory combustion was considered possible, but no evidence of its occurrence was obtained. The spectral shape is similar to the jet-noise spectra for rockets and turbojet engines as reported in published literature.

The measured-sound pressure levels for the duct-vault inerting wall and the weather doors at ETS-1 agree quite well with the calculated values; the actual levels are about $1 \mathrm{db}$ lower than those that were predicted. The tabulated results of the measurements, a sketch of the duct model and test stand, a photograph of the exhaust plume, schematics of the data-processing system, spectral-density profiles, and the relation of sound to mechanical power are included. Also included is a suggested method of analysis when a substantial combustion contribution is expected. Statistical analysis of the acoustic power shows that the variation in acoustic efficiency is reduced if a thermalmechanical theoretical model is utilized rather than the conventional theoretical model of a noise-radiating jet. 


\section{TABLE OF CONTENTS}

$\underline{\text { Page }}$

I. Introduction

1

II. Description of Test Facilities $\quad 6$

III. Scope of Data Obtained 13

IV. Experimental Procedures $\quad 22$

V. Results of Data Analysis $\quad 28$

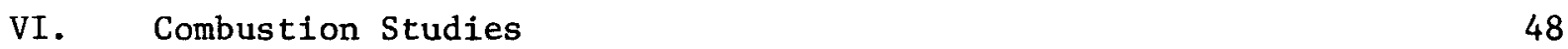

VII. Comparison of Predicted and Actual Sound Pressure Levels 50

VIII. Recommended Prediction Method 53

IX. Conclusions $\quad 56$

References $\quad 58$

TABLE LIST

No. $\quad$ Page

1 Run Conditions for XE Tests at ETS-1 14

2 Calibration History of Acoustic Instruments $\quad 16$

3 Acoustic System Frequency Response 17

4 Duct-Exit Flow Parameters for Tests A2 through A21 18

5 Local Climatological Data 26

$6 \quad$ Sound Pressure Levels $\quad 37$ 


\section{FIGURE LIST}

No.

1 Original ETS-1 Inerting Wall and NES Duct

2 New ETS-1 Inerting Wall and NES Duct

3 NES Duct

4 Instrumentation Location, Acoustic Tests 1

5 Isometric Sketch of Test Facilities 10

6 Microphone and Adapter 11

$7 \quad$ Schematic of the Acoustic Data-Reduction System 12

8 Burning Exhaust Plume from the NES Duct 23

9 Overall Sound Pressure Level, Microphone $116 \quad 32$

10 Sound Spectra for Microphone 113

11 Sound Spectra for Microphone 114

12 Sound Spectra for Microphone 115

13 Sound Spectra for Microphone $116 \quad 36$

14 Octave-Band Pressure Leve1, Test EP-2A 40

15 Octave-Band Pressure Leve1, Test EP-3 41

16 Octave-Band Pressure Level, Test EP-5C 42

17 Octave-Band Pressure Leve1, Test EP-6C 43

18 Octave-Band Pressure Level, Test EP-9 44

19 Relation of Sound Power and Mechanical Power 46

20 Comparison, Measured and Predicted Sound Pressures 52 


\section{INTRODUCTION}

Testing of the experimental cold flow engine (XECF) in ETS-1 resulted in slight damage to the corrugated aluminum sheet metal of the duct-vault inerting wall. Screws that hold the sheet metal to the frame had backed out in some places while in other locations the sheet metal had torn loose around the screws. This damage, though slight, occurred at sound pressure levels, flow rates, and gas temperatures that were substantially less than those anticipated for full-power engine testing. Various causes for the damage were suggested: jet noise, combustion overpressures, heat radiation, and static pressure differentials. A comprehensive investigation of the damaged areas indicated that sound pressure waves generated by the duct effluent with the unsteady combustion of the duct effluent hydrogen during certain portions of the test were primarily responsible for the damage. A photograph of the wall was taken after this test series and is shown in Figure 1.

To determine the extent of the noise field resulting from the testing of a nuclear rocket engine, Aerojet-General Corporation in JuIy 1968 began an extensive program to identify the factors necessary to define the acoustics by using scale-model experiments and taking acoustic measurements during tests of the nuclear rocket engine while it is operating at various reactor power levels. This report describes the results of the full-scale power tests, including the full-power run conducted in ETS-1 on June 11, 1969. The results of the scale-model tests were previously described ${ }^{(1) *}$.

During consultations with SNPO and a group experienced in acoustic problems (Paul S. Veneklasen and Associates, LASL, and Marshall Space Flight Center) an approach was formulated to set the objectives for the investigation and these are:

* Numbers in parentheses refer to references 


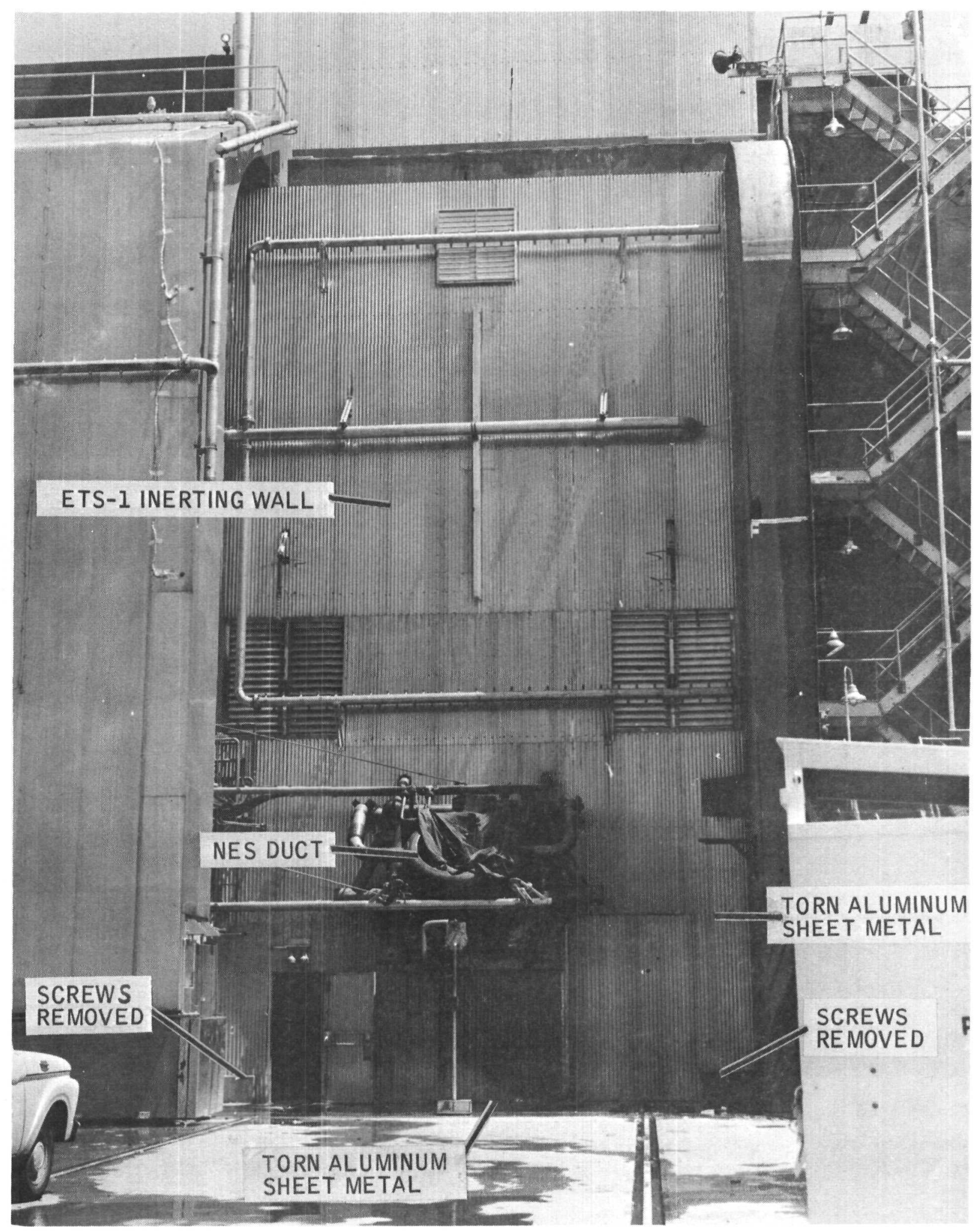

Figure 1 - Original ETS-1 Inerting Wa11 and NES Duct 
1. Define the acoustic fleld near the duct.

2. Identify problem areas in ETS-1 during partial-power runs.

3. Modify the theoretical model and state-of-the-art methods if necessary.

4. Identify and investigate evidence of oscillatory combustion.

A survey of related experience applicable to this problem was conducted. The acoustic field for a nuclear-rocket nozzle exhausting directly to the atmosphere (KIWI B) was studied by Manhart et a1. ${ }^{(2)}$; in this case the hightemperature exhaust gases from the nozzle were directed vertically upwards with an exit velocity of 5000 to $20,000 \mathrm{ft} / \mathrm{sec}$. The mass-flow rate (helium and hydrogen) varied from 35 to $85 \mathrm{lb} / \mathrm{sec}$. However, the NES duct cools and dilutes the nozzle hydrogen with steam and discharges it to the atmosphere with a flow direction approximately $40^{\circ}$ to the horizontal and with a velocity that varies from 200 to $6000 \mathrm{ft} / \mathrm{sec}$. The two nuclear-exhaust systems are thus basically dissimilar.

Acoustic data on subsonic jets, with and without combustion, have been compiled by Lighthill (3), and Washburn and Fenstermacher ${ }^{(4)}$. However, the jets involved were much smaller than the NES duct and combustion was either stable or non-existent. Mayes and Lanford ${ }^{(5)}$ and overton ${ }^{(6)}$ compiled data on the noise produced by rocket engines firing at thrust levels from 1000 to $1,000,000 \mathrm{lb}$. Grande ${ }^{(7)}$ considered the effect of directivity on scaling hot and cold jets as well as the characteristics of the noise spectra and the total acoustic power. A comprehensive summary of directivity functions for subsonic jets (air and turbojet exhaust), as well as supersonic jets, was compiled by Howes ${ }^{(8)}$. Study of the cited and other available references, however, indicates a lack of information on the parameters that are important to the determination of the pressures on the test stand such as the effect of mixing steam and hydrogen, velocity distribution in the exit plane, and limits of combustion stability; further, data from different sources disagree by as much as $10 \mathrm{db}$. The data obtained during this investigation are thus unique in a number of ways. These include the flow-jet angle, variations in the effluentgas-mixture ratio, and the near-field environment. 
As a result of the studies and analyses performed prior to power tests in ETS-1, a theoretical model was developed, acoustic and structural studies were completed, and a structurally improved wall was designed and installed. A photograph of this wall is shown in Figure 2. 


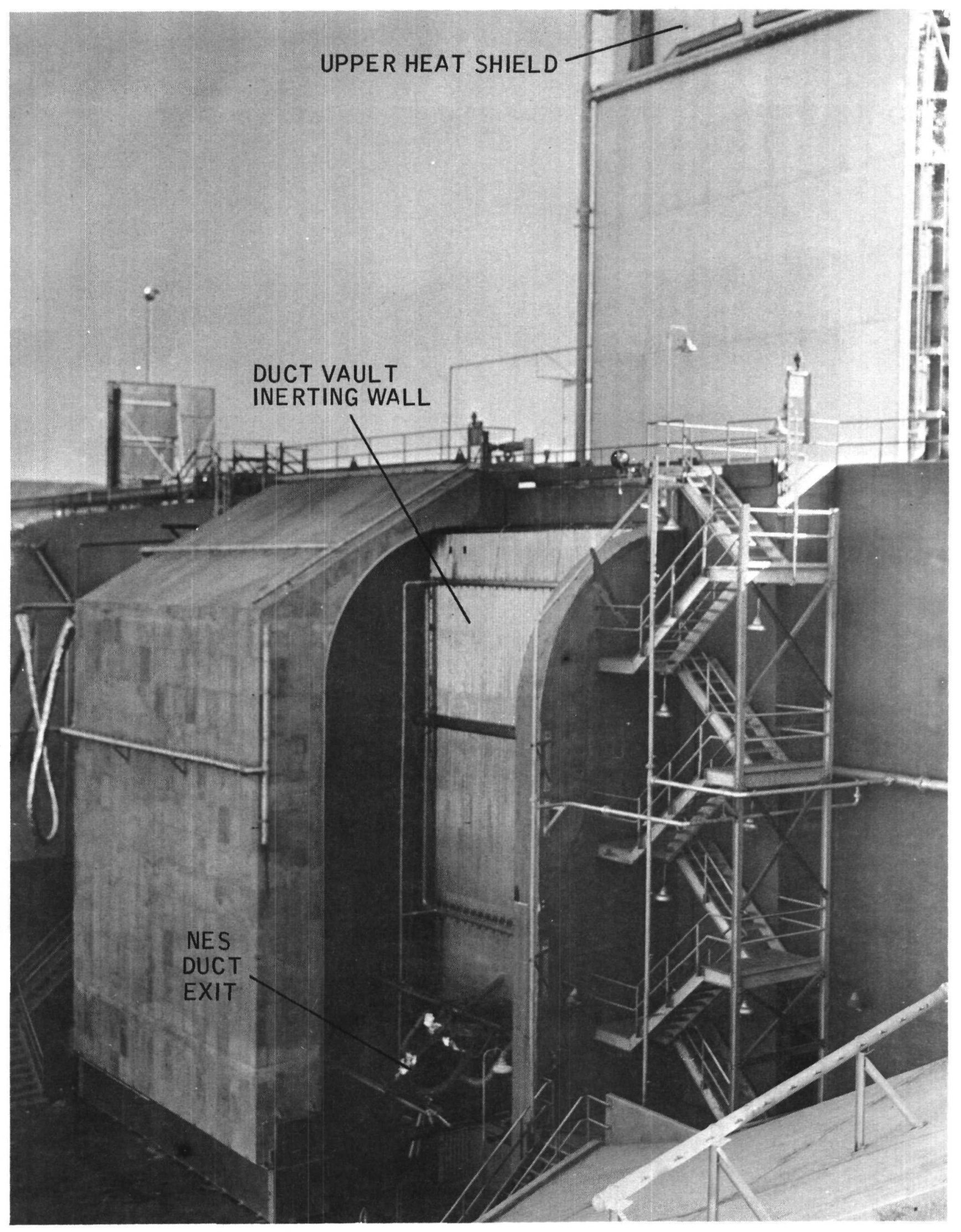

Figure 2 - New ETS-1 Inerting Wa11 and NES Duct 
II. DESCRIPTION OF TEST FACILITIES

A. DUCT

The NES duct at NRDS consists of a supersonic diffuser, $90^{\circ}$ subsonic turning elbow, steam ejector, mixing section, and a $45^{\circ}$ discharge elbow as shown in Figure 3. The stand is equipped with transducers to measure engine, steamejector, contro1, safety, and environmental parameters. Measurements of the gas and steam flow rates, pressures, and temperatures are performed at eight locations in the facility and four in the ETC. These measurements are necessary to identify the duct-exit gas conditions.

\section{B. GAS SUPPLY}

Hydrogen gas in the duct is provided by the engine at flow rates to $80 \mathrm{lb} / \mathrm{sec}$. Steam (the ejector fluid) is provided from combustion of oxygen and propane further quenched with water. The term steam is used herein to conform to standard practice, but the fluid is not entirely steam, having a molecular weight of about $19 \mathrm{Ib} / \mathrm{lb} \mathrm{mol}$. The upper temperature limit of hydrogen in the engine is $4100^{\circ} \mathrm{R}$, and that of the steam generator products is $1660^{\circ} \mathrm{R}$

The engine and facility control consoles are located in a blockhouse adjacent to ETS-1. Flow rates and all other parameters are controlled through these consoles.

\section{MICROPHONE SYSTEM, CALIBRATIONS AND TAPE RECORDERS}

Four Kaman Nuclear Model KM1800-1 microphones were used in the study. Three, designated near field, were positioned at location numbers 113, 115, and 116 as shown in Figure 4. One, designated far field, was positioned 


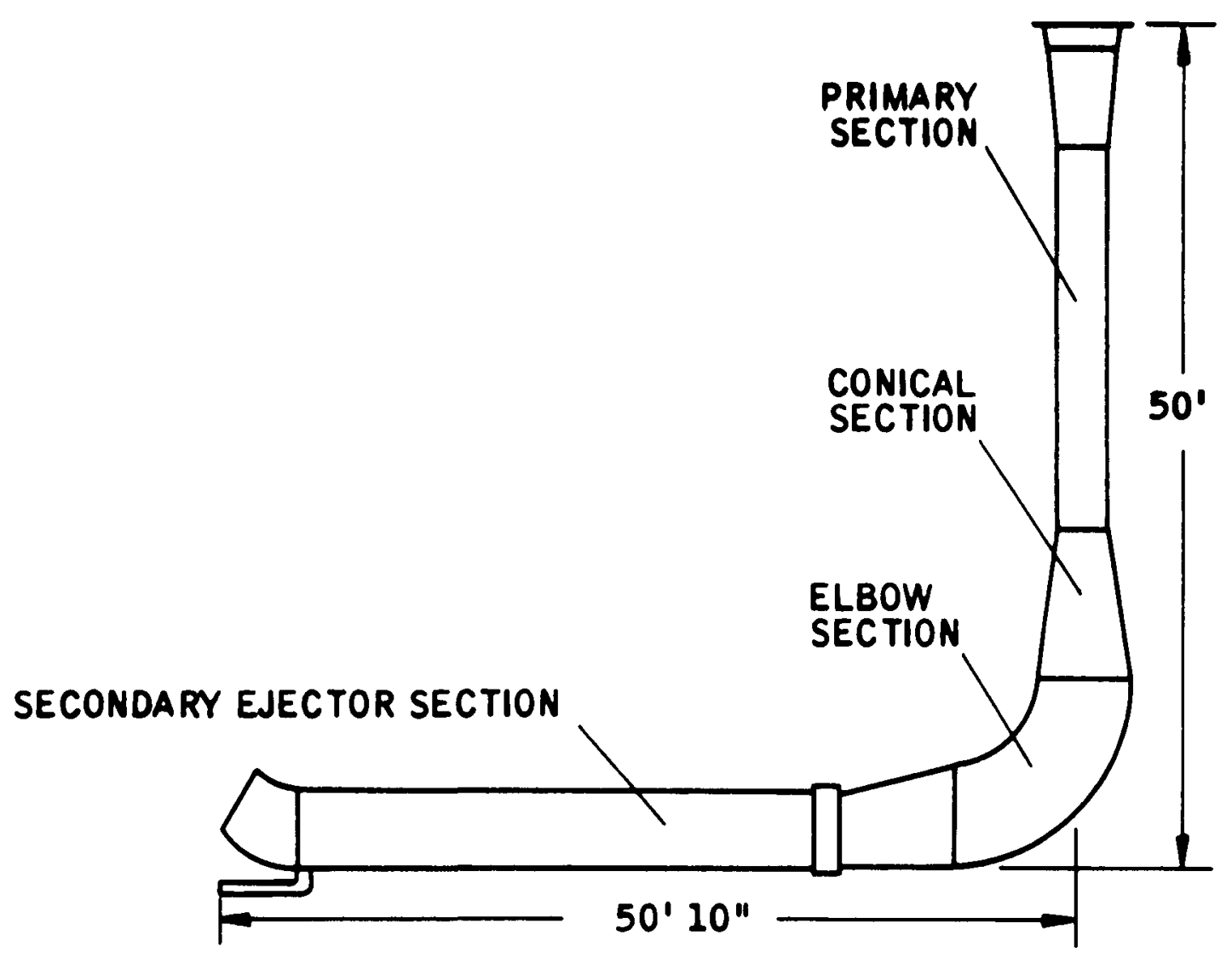

Figure 3 - NES Duct 


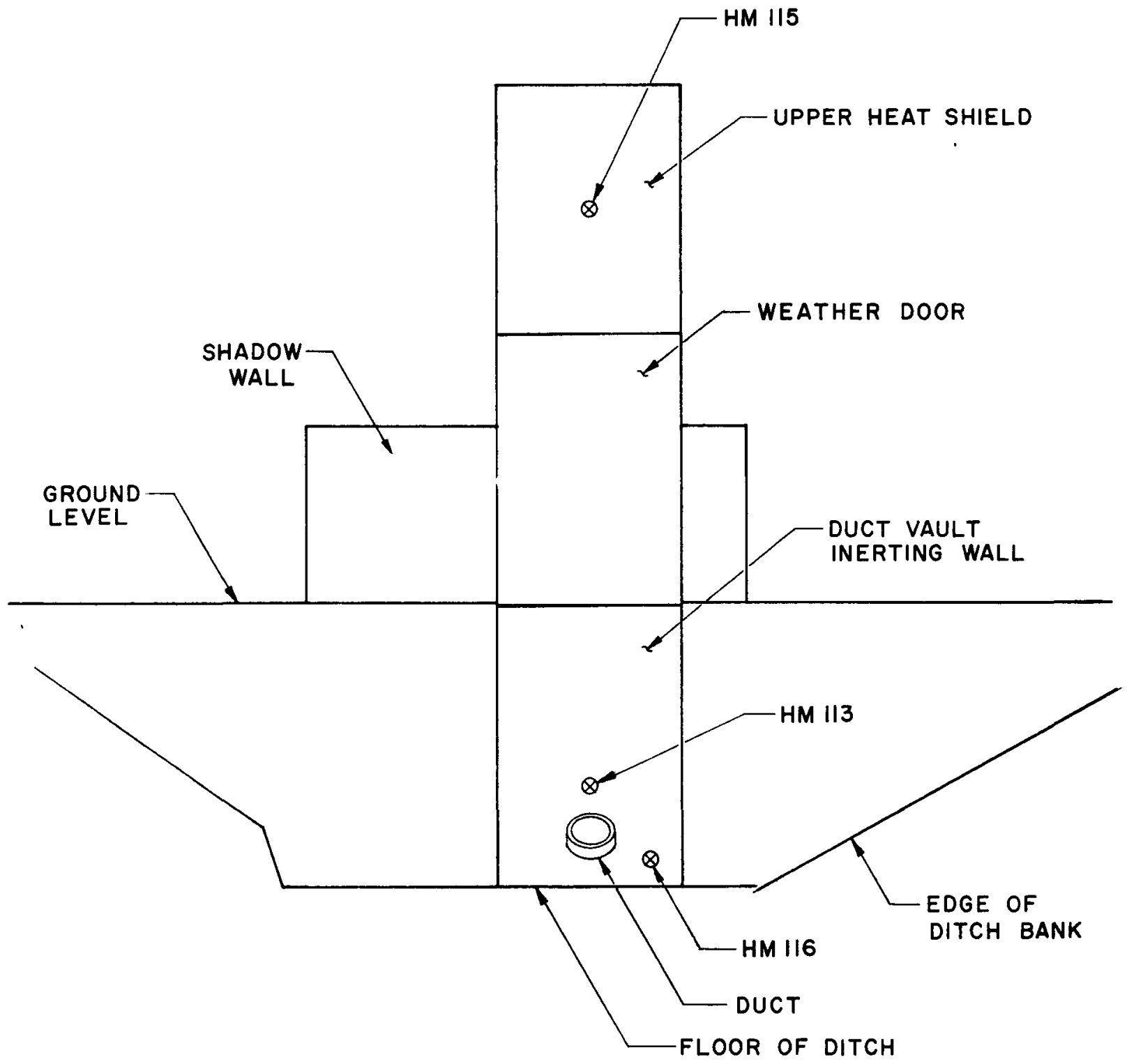

Figure 4 - Instrumentation Location, Acoustic Tests 
at location number 114. All four contalned identical transducers, which could measure static and dynamic pressures from 88 to $180 \mathrm{db} r e^{*} 0.0002 \mathrm{dyne} / \mathrm{sq} \mathrm{cm}$ at frequencies from 0 to $20,000 \mathrm{~Hz}$. An isometric sketch of the facility is shown in Figure 5. Preamplifiers were provided because of the long cables required. Al1 microphones were supported by rubber shock-absorbing mountings to insure isolation from the support. A typical microphone is shown in Figure 6 .

The sound pressure signals were amplified on facility amplifiers and recorded on magnetic tape. A schematic of the data system is shown in Figure 7. The final data playback was performed after the test on a Bruel and Kjaer system for presentation either as overall or octave-band sound pressure or in terms of frequency-spectrum pressure levels.

The tape playback unit was a Honeywell 7600. The signal from the tape was processed on a Bruel and Kjaer 221 Spectrometer; a true RMS Level Voltage Recorder was utilized for the overall sound pressure-level studies. For calibration, electrical and sound-wave signals were available. Electrical calibration was rejected as a primary calibration source for the microphones because of the inability to calibrate the most questionable component in the system, the microphone itself. A General Radio Sound Level Calibrator, Type 1562-A, was selected for the sound source as a calibration standard.

*The decibel is a dimensionless unit used to express a logarithmic ratio between a measured quantity and a reference quantity. For example, sound pressure level $(\mathrm{SPL})$ in decibels $=20 \log \left(\mathrm{P}_{1} / \mathrm{P}_{0}\right)$ where $\mathrm{P}_{1}=$ measured rms pressure in dynes $/ \mathrm{cm}^{2}$ and $\mathrm{P}_{\mathrm{O}}=$ reference pressure of 0.0002 dynes $/ \mathrm{cm}^{2}$. This is conveniently written as SPL, db re 0.0002 dynes $/ \mathrm{cm}^{2}$. 


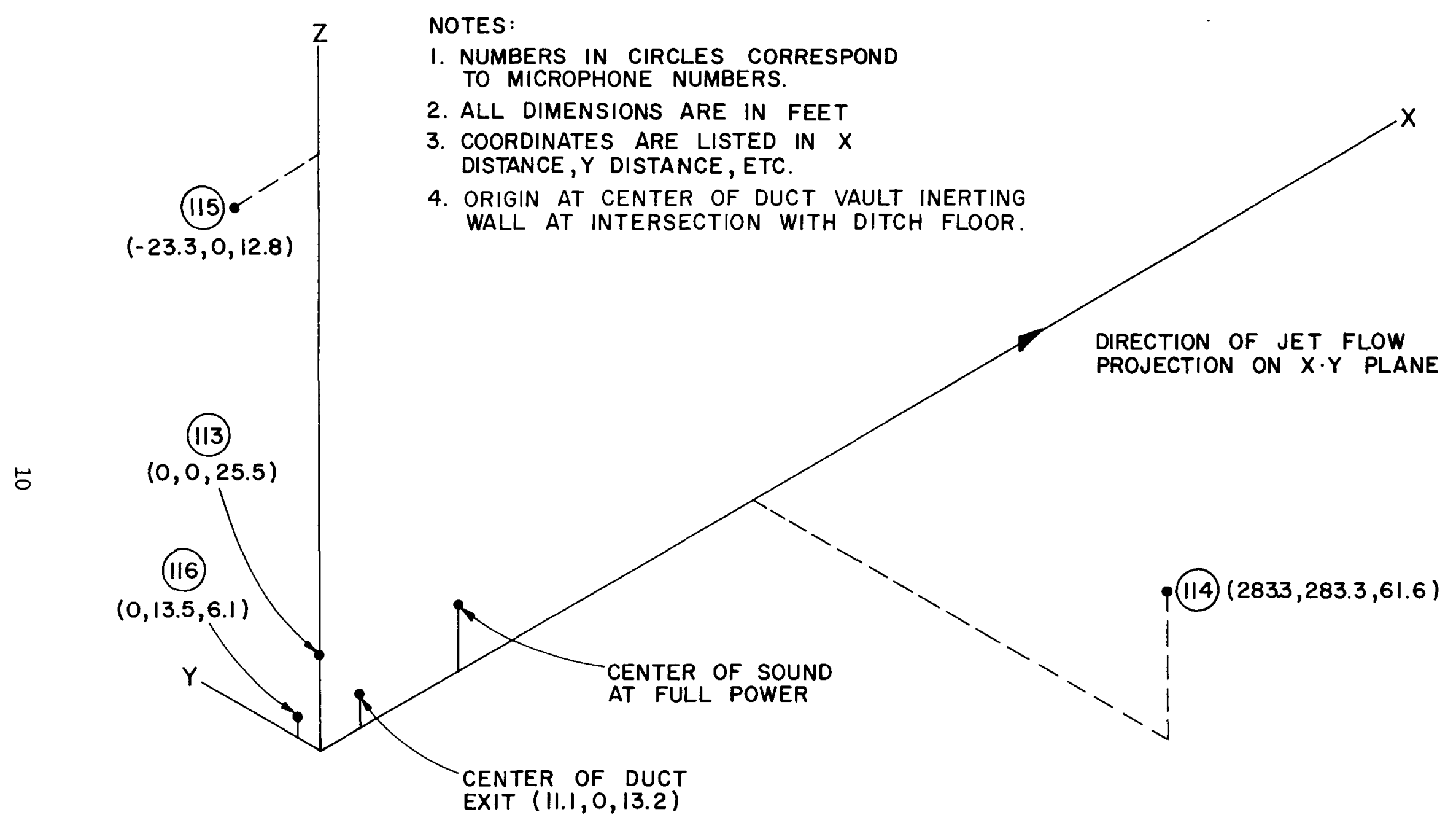

Figure 5 - Isometric Sketch of Test Facilities 


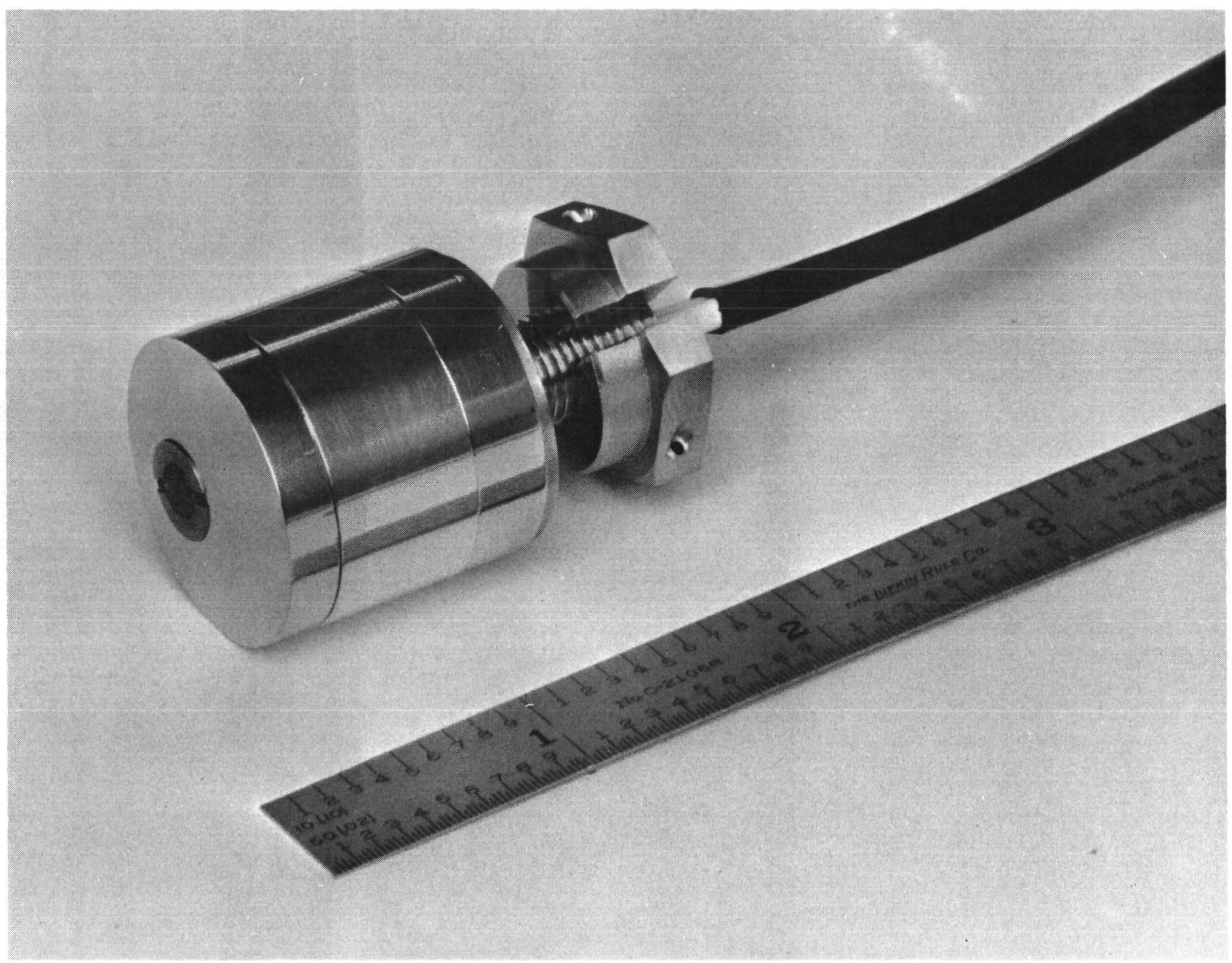

Figure 6 - Microphone and Adapter 


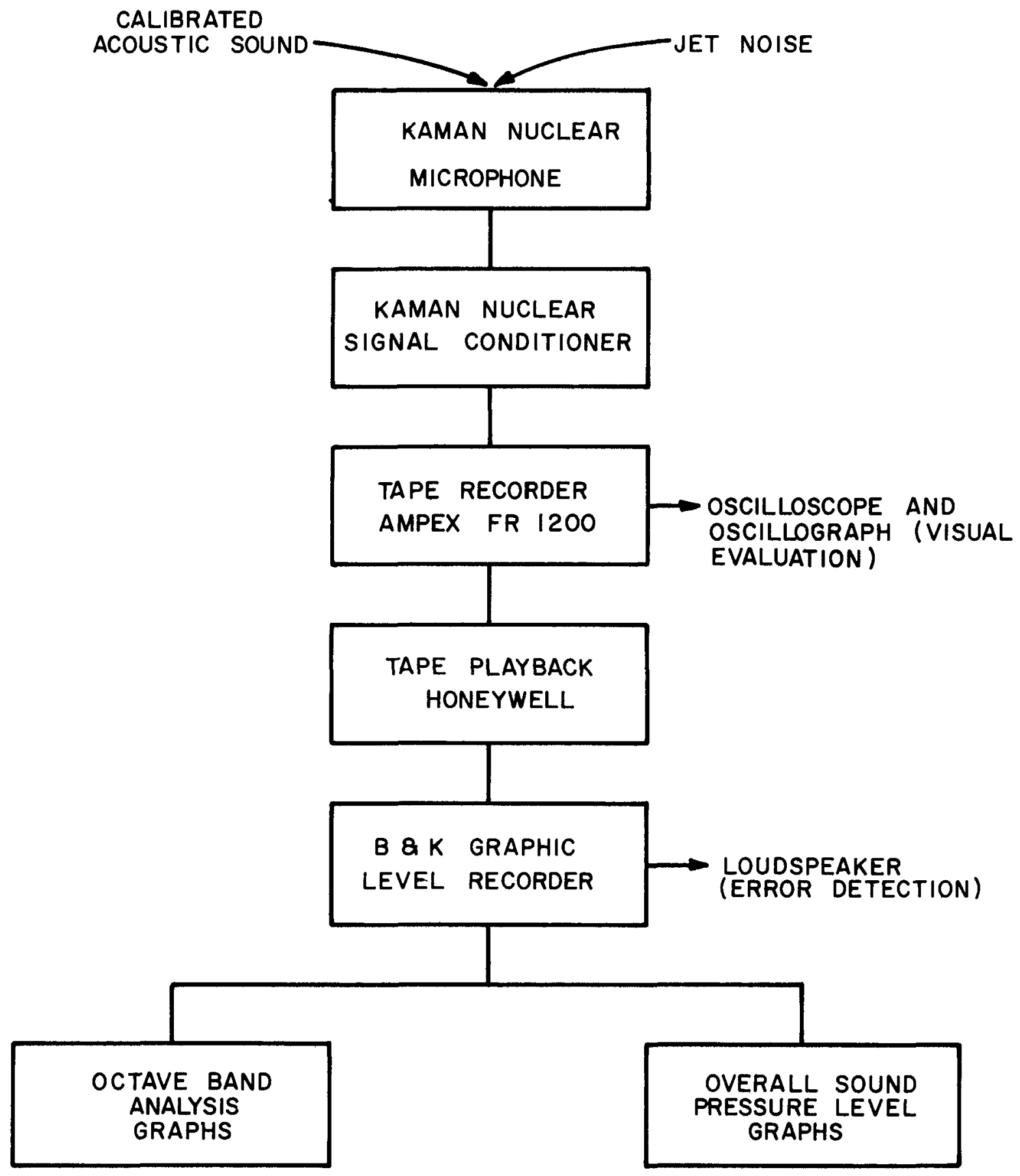

Figure 7 - Schematic of the Acoustic Data-Reduction System 
III. SCOPE OF DATA OBTAINED

A. EXPERIMENTAL PROCEDURE

The $\mathrm{XE}$ tests for which acoustic data were analyzed had the following objectives:

Test No. EP-2A - Transient-flow bootstrap tests

Test No. EP-3 - Steady-flow intermediate power

Test No. EP-5C - Steady-flow full power

Test No. EP-6A - Transient-flow startup tests

Test No. EP-9A - Steady-flow high-I tests

The complete range of test variables is:

Engine Gas

Species

Hydrogen

Flow Rate, $1 \mathrm{~b} / \mathrm{sec}$

0 to 80

Temperature, ${ }^{\circ} \mathrm{R}$

to $4100^{\circ} \mathrm{R}$

Ejector Gas

$\begin{array}{ll}\text { Species } & \text { Most1y steam } \\ \text { Flow Rate, 1b/sec } & 120 \text { to } 160 \\ \text { Temperature, }{ }^{\circ} \mathrm{R} & 540 \text { to } 1600\end{array}$

Duct Geometry

Exit diameter, ft $\quad 4.33$

Exit Angle, degrees 45

A more complete listing of the tests conducted and the flow conditions is given in Table 1 . 
TABLE 1

RUN CONDITIONS FOR XE TESTS AT ETS-1

Sound Leve1 Measurements on Test Stand

\begin{tabular}{|c|c|c|c|c|c|c|c|}
\hline \multirow[b]{2}{*}{ Date } & \multirow[b]{2}{*}{ Test } & \multirow[b]{2}{*}{$\begin{array}{l}\text { Time } \\
\text { sec. }\end{array}$} & \multirow{2}{*}{$\begin{array}{c}\text { Engine } \\
\text { Temp } \\
{ }^{\circ} \mathrm{R} \\
\end{array}$} & \multirow{2}{*}{$\begin{array}{r}\text { Gas } \\
\text { F1ow } \\
\text { Pps } \\
\end{array}$} & \multicolumn{2}{|c|}{ Steam } & \multirow[b]{2}{*}{$\begin{array}{c}\text { Diluent } \\
\text { Gases } \\
\end{array}$} \\
\hline & & & & & $\begin{array}{c}\text { Temp } \\
{ }^{\circ} \mathrm{R} \\
\end{array}$ & $\begin{array}{r}\text { F1ow } \\
\text { Pps }\end{array}$ & \\
\hline $3 / 20$ & $2 \mathrm{~A}$ & 29270 & 500 & 0 & 1100 & 138 & $\mathrm{~N}_{2}$ \\
\hline $3 / 20$ & $2 \mathrm{~A}$ & 49350 & 500 & 0 & 1150 & 137 & $\mathrm{~N}_{2}$ \\
\hline $3 / 20$ & $2 \mathrm{~A}$ & 49450 & 1280 & 16 & 1200 & 137 & $\mathrm{~N}_{2}$ \\
\hline $3 / 20$ & $2 A$ & 49478 & 1350 & 21 & 1200 & 137 & $\mathrm{~N}_{2}$ \\
\hline
\end{tabular}

$\begin{array}{rrrrrrrr}4 / 16 & 3 & 54625 & 530 & 2 & 1330 & 134 & \mathrm{~N}_{2} \\ 4 / 16 & 3 & 54900 & 3050 & 38 & 1360 & 134 & \mathrm{~N}_{2} \\ 4 / 16 & 3 & 54990 & 2350 & 33 & 1360 & 134 & \mathrm{~N}_{2} \\ 4 / 16 & 3 & 55250 & 1050 & 2 & 1390 & 133 & \mathrm{~N}_{2}\end{array}$

$\begin{array}{llllllll}6 / 11 & 5 \mathrm{C} & 38500 & 540 & 3 & 1350 & 139 & \mathrm{~N}\end{array}$

$\begin{array}{lllllll}6 / 11 & 5 \mathrm{C} & 38800 & 2380 & 44 & 1360 & 140\end{array}$

$\begin{array}{lllllll}6 / 11 & 5 \mathrm{C} & 38930 & 4100 & 71 & 1360 & 142\end{array}$

$\begin{array}{lllllll}6 / 11 & 5 C & 39200 & 1960 & 29 & 1340 & 142\end{array}$

$\mathrm{N}_{2}$

$142 \quad \mathrm{~N}_{2}$

$142 \quad \mathrm{~N}_{2}$

$\begin{array}{rrrrrrr}7 / 10 & 6 \mathrm{~A} & 44320 & 500 & 0 & 1280 & 155 \\ 7 / 10 & 6 \mathrm{~A} & 44520 & 1700 & 24 & 1290 & 158 \\ 8 / 28 & 9 & 59200 & 200 & 0 & 1350 & 132 \\ 8 / 28 & 9 & 59810 & 3990 & 38 & 1370 & 135\end{array}$


Prior to tests, the microphones were returned to the factory for a complete re-calibration from 0 to $10,000 \mathrm{~Hz}$ and 60 to $180 \mathrm{db}$ frequency range and sound pressure level. Prior to each test, the test-operation procedure required a pretest calibration from 100 to $160 \mathrm{db}$ at $1000 \mathrm{~Hz}$ for each microphone. However, lateness of the hour or equipment demands sometimes forced deviations from this procedure. Calibration history is presented in Table 2. This procedure was restricted to the sound-pressure measurements as other instruments are inherently more reliable and are calibrated by facility personnel on a periodic basis. Because the validity of the test results is limited not only by the microphones, but also to their associated amplifiers, pre-amplifiers, tape recorders, and cable, special attention was directed to the secondary components. The overall response of the system was determined by experiment to be quite flat from 1 to $20 \mathrm{~K} \mathrm{~Hz}$ for all microphones. The data shown in Table 3, indicates that the microphones limit the system response.

\section{B. METHOD OF CALCULATION OF FLOW PARAMETERS}

The results of the tests and the conclusions drawn are based on the gas flow conditions at the duct exit and the resulting sound pressure levels; however, only the sound pressure levels were directly measured. The other quantities are calculated from measured pressures, temperatures, etc. To enable other investigators to make use of the data independently at some later date, a summary of the method of calculation of the gas-mass flow rate, jetmechanical power, and gas-effluent extt veloclty is described fully in Appendix $A^{(1)}$. A summary of duct exit conditions so calculated is presented in Table 4.

\section{METHOD OF CALCULATION OF ACOUSTIC EFFICIENCIES}

Sound pressure levels were measured using microphones, and jet powers were calculated as given by the formulas in Appendix $B{ }^{(1)}$. The expression for the mechanical-to-total acoustic power conversion efficiency was obtained from the measured-sound pressure level*, the calculated fet mechanical

*Both far and near field values were utilized in the calculation of acoustic power and acoustic efficiencies. 
TABLE 2

CALIBRATION HISTORY OF ACOUSTIC INSTRUMENTS

\begin{tabular}{|c|c|c|c|c|c|}
\hline Test & Date & Microphone & Positions* & $\begin{array}{l}\text { Frequency } \\
\mathrm{Hz}\end{array}$ & $\begin{array}{c}\text { Calibration } \\
\text { Range } \\
\mathrm{db} \\
\end{array}$ \\
\hline $2 \mathrm{~A}$ & $3 / 19$ & 113,114, & 115,116 & 1000 & 110 to 160 \\
\hline 3 & $4 / 15$ & 113,114 , & 115,116 & 1000 & 110 to 160 \\
\hline $5 \mathrm{C}$ & $6 / 10$ & 113,116 & & 1000 & 130 to 160 \\
\hline $5 \mathrm{C}$ & $6 / 10$ & 114,115 & & 1000 & 120 to 140 \\
\hline $6 \mathrm{~A}$ & $7 / 9$ & 113,116 & & 1000 & 120 to 150 \\
\hline $6 \mathrm{~A}$ & $7 / 9$ & 114,115 & & 1000 & 100 to 130 \\
\hline
\end{tabular}


TABLE 3

ACOUSTIC SYSTEM FREQUENCY RESPONSE

From Microphone to Spectral Analyses

\begin{tabular}{|c|c|c|c|c|c|}
\hline $\begin{array}{c}\text { Manuf acturer } \\
\text { and Name } \\
\end{array}$ & $\begin{array}{l}\text { Mode1 } \\
\text { No. }\end{array}$ & $\begin{array}{l}\text { Microphone } \\
\text { Position } \\
\end{array}$ & $\begin{array}{c}\text { Type of } \\
\text { Calibration } \\
\mathrm{K} \mathrm{Hz} \\
\end{array}$ & $\begin{array}{l}\text { Output* } \\
\mathrm{db}\end{array}$ & $\begin{array}{c}\text { Sensitivity } \\
\text { for Maximum } \\
\text { Record Leve1 } \\
\mathrm{db} \\
\end{array}$ \\
\hline $\begin{array}{l}\text { Kaman Nuclear } \\
\text { System }\end{array}$ & $\begin{array}{l}\text { KM1800-1 } \\
\text { K3011 }\end{array}$ & A11 & 0.001 to 5 & \pm 3.0 & 180 \\
\hline $\begin{array}{l}\text { ETS-1 Data } \\
\text { System }\end{array}$ & Various & Al1 & 0.001 to 5 & $\begin{array}{l}0 \\
\pm 2.0\end{array}$ & \\
\hline $\begin{array}{l}\text { Ampex Tape } \\
\text { Recorder }\end{array}$ & FR1200 & A11 & 0 to 5 & \pm 1.0 & \\
\hline $\begin{array}{l}\text { Honeywell Tape } \\
\text { Player }\end{array}$ & 1760 & A11 & 0 to 20 & \pm 0.5 & \\
\hline $\begin{array}{l}\text { Bruel and Kjaer } \\
\text { RMS Indicator }\end{array}$ & 2211 & A11 & 0 to 20 & \pm 1.0 & \\
\hline
\end{tabular}

*Variation In output for a constant level input signal which varies over the specifled frequency range, including $500 \mathrm{ft}$ of line for the tape recorder. 
TABLE 4

\section{Duct Exit Flow Parameters for XE Tests}

Run No.

Time, sec

Engine Gas, $\mathrm{GH}_{2}$

\begin{tabular}{|c|c|c|c|c|c|c|c|c|c|c|c|c|c|c|c|c|}
\hline Totai Temperature, ${ }^{\circ} \mathrm{R}$ & 500 & 500 & 1275 & 1350 & 527 & 3050 & 2345 & 1059 & 540 & 2380 & 4100 & 1956 & 500 & 1700 & 200 & 3985 \\
\hline Flow Rate, pps & 0 & 0 & 15.8 & 20.5 & 1.83 & 38.0 & 32.6 & 2.33 & 3.0 & 44.4 & 70.5 & 28.8 & 0 & 24.4 & 0 & 38.2 \\
\hline Total Temperature, ${ }^{\circ} \mathrm{R}$ & 510 & 500 & 270 & 151 & 521 & 418 & 351 & 583 & 315 & 509 & 844 & 238 & 500 & 158 & 325 & 501 \\
\hline Flow Rate, pps & 0 & 0 & 0.98 & 1.97 & 0 & 4.26 & 3.69 & 0.099 & 0.10 & 4.43 & 7.37 & 2.70 & 0 & 2.30 & 0 & 3.68 \\
\hline Totai Temperature, ${ }^{\circ} \mathrm{R}$ & 520 & 520 & 520 & 520 & 520 & 520 & 520 & 519 & 519 & 519 & 519 & 519 & 520 & 520 & 520 & 520 \\
\hline Flow Rate, pps & 6 & 6 & 6 & 6 & 6 & 6 & 6 & 1.61 & 1.61 & 1.61 & 1.61 & 1.61 & 0 & 0 & 0 & 0 \\
\hline & & & & & & & & & & & & & & & & \\
\hline Total Temperature, ${ }^{\circ} \mathrm{R}$ & 1103 & 1168 & 1205 & 1203 & 1333 & 1359 & 1364 & 1388 & 1350 & 1356 & 1358 & 1342 & 1275 & 1294 & 1347 & 1371 \\
\hline Flow Rate, pps & 138.3 & 137.6 & 137.4 & 137.3 & 134.5 & 134.3 & 134.0 & 133.3 & 138.9 & 139.6 & 142.4 & 142.1 & 155.0 & 158.0 & 132.2 & 135.0 \\
\hline
\end{tabular}

\section{Duct Exit Gas}

Flow Rate, pps

Molecular weíght

Total Temperature, ${ }^{\circ} \mathrm{R}$

Ratio Speciftc Heats

Mach Number

Velocity, tt per sec

$\mathrm{GH}_{2}$ Flow, $\mathrm{pps}$

$\frac{2 \mathrm{~A}}{49270} \frac{2 \mathrm{~A}}{49350} \frac{2 \mathrm{~A}}{49450} \frac{2 \mathrm{~A}}{49478} \frac{3}{54625} \frac{3}{54900} \frac{3}{54990} \frac{3}{55250} \frac{5 \mathrm{C}}{38500} \frac{5 \mathrm{C}}{38800} \frac{5 \mathrm{C}}{38930} \frac{5 \mathrm{C}}{39200} \frac{6 \mathrm{~A}}{44320} \frac{6 \mathrm{~A}}{44520} \frac{9}{59200} \frac{9}{59810}$

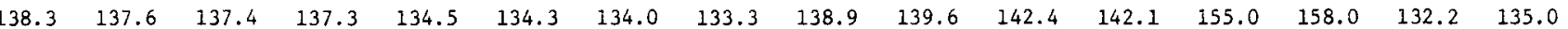

\begin{tabular}{|c|c|c|c|c|c|c|c|c|c|c|c|c|c|c|c|}
\hline 144.3 & 143.6 & 150.1 & 165.8 & 142.3 & 183.2 & 176.3 & 141.7 & 143.7 & 190.0 & 221.9 & 175.2 & 155.0 & 184.7 & 132.2 & 176.9 \\
\hline 19.84 & 19.84 & 10.30 & 9.14 & 19.39 & 6.52 & 7.23 & 17.36 & 16.41 & 6.04 & 4.78 & 7.55 & 19.50 & 8.65 & 19.38 & 6.37 \\
\hline 1043 & 1108 & 1093 & I110 & 1158 & 2111 & 1656 & 1220 & 1168 & 1764 & 3053 & 1445 & 1215 & 1324 & 1287 & 2659 \\
\hline 1.285 & 1.285 & 1.333 & 1.334 & 1.269 & 1.287 & 1.337 & 1.296 & 1.300 & 1.343 & 1.287 & 1.339 & 1.284 & 1.355 & 1.286 & 1.287 \\
\hline .2195 & .2251 & .3376 & .3722 & .2427 & .6714 & .5602 & .2628 & .2541 & .6466 & 1.000 & .4838 & .2566 & .4632 & .3303 & .7319 \\
\hline 401 & 423 & 887 & 1044 & 489 & 2960 & 2129 & 556 & 542 & 2757 & 6395 & 1692 & 509 & 1450 & 970 & 3643 \\
\hline 1.13 & 1.13 & 17.97 & 23.55 & 3.24 & 43.67 & 37.70 & 3.84 & 4.56 & 50.27 & 79.37 & 33.06 & 1.44 & 28.12 & 1.45 & 43.36 \\
\hline
\end{tabular}

* Summation of engine and turbine flows plus equilibriurn hydrogen formed in the "steam". 
power, the measured distance, and the calculated directivity index. It was then assumed that the measured acoustic power equals the sum of the acoustic power due to jet-gas mechanical power and the jet-gas thermal power due to combustion. The thermal-to-acoustic power conversion efficiency was obtained from the calculated jet mechanical power, jet thermal power, total acoustic power conversion efficiency, and assumed mechanical-to-acoustic power conversion efficiency. The procedure is described below:

\section{Nomenclature}

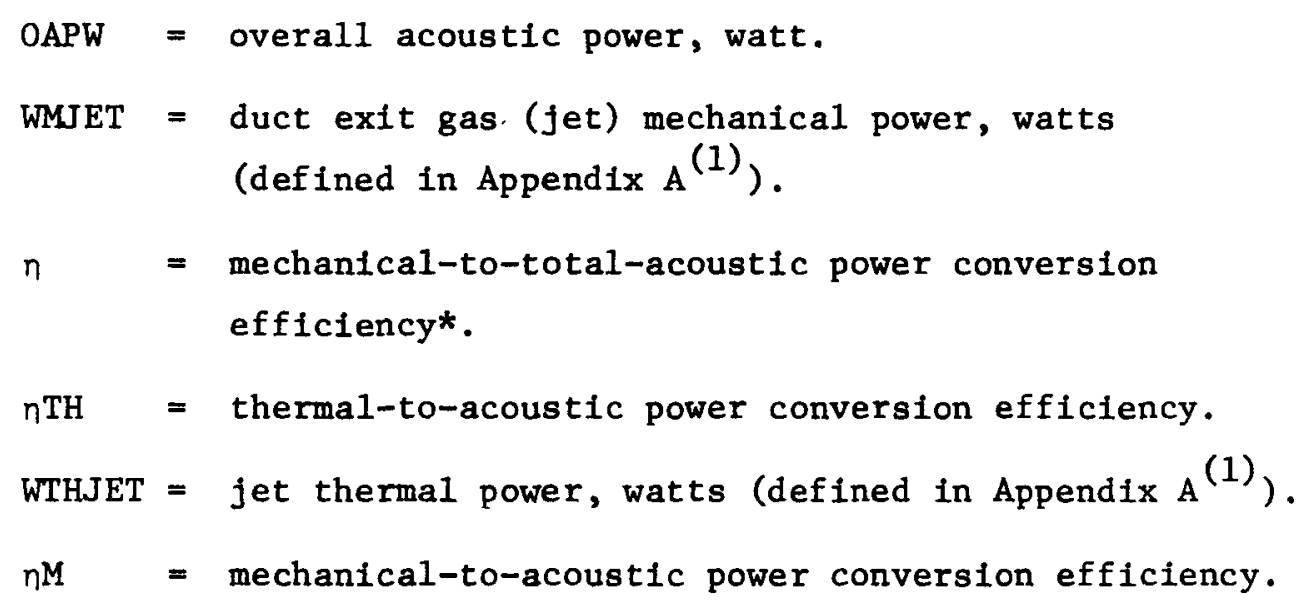

2. Analysis

One ideal model of the acoustic process, the mechanical model, is applicable to all fets. This visualizes all acoustic power as emanating from component power terms that are themselves proportional to the jet mechanical power; therefore, by this model (in FORTRAN notation),

$$
\text { OAPW }=n * \text { WMJET }
$$

This equation can also be used as the definition of the acoustic conversion efficiency.

\footnotetext{
*For brevity and to conform to standard practice this parameter is called the acoustic conversion efficiency in this report.
} 
Another ideal model of the acoustic process, the thermalmechanical mode1, is applicable only to burning fets. This visualizes all acoustic power as emanating from two component power terms and is calculable as the sum of each taken separately. These component terms are each assumed proportional to the jet mechanical power and the jet thermal power. By this model,

$$
\mathrm{OAPW}=\eta \mathrm{TH} * \mathrm{WTHJET}+\mathrm{nM} * \mathrm{WMJET}
$$

Equations (1) and (2) are combined to show the relationship between the three efficiencies.

$$
\eta \quad=n T H * \text { WTHJET } / \text { WMJET }+\eta M
$$

Equation (3) shows that if the jet power terms or their ratio and the thermal efficiency are constant, a change in the mechanical-to-acoustic power conversion efficiency produces a corresponding change in the total acoustic power conversion efficiency.

\section{Discussion}

Equation (1) Is obtained from the application of acoustic principles to the first model described and equation (2) similarly is obtained from the second model. From a scientific viewpoint the second model appears to offer the best approach, that is, the two component efficiencles should be closer to constant values for a given change in gas mixture ratio than is the total acoustic efficiency.

D. ACOUSTIC SPECTRAL DISTRIBUTION

For each test, one reel of tape was used to record all pre and post calibrations as well as the data signals. Calibration provided a means of determining the amplitude and frequency response of each data-analysis 
channel. Comparison of the pre and post calibration signal gave assurance that the sensitivity of each channel did not change during the test.

Overall acoustic efficiency was determined as described above, assuming a value for the directivity index. Figure 4 shows that not enough microphones were available to reliably determine sound power levels without prior knowledge of directivity index. Spectral distribution was determined from octave-band plots using the Bruel and Kjaer Graphic Level Recorder Type 2305.

\section{E. EXHAUST VELOCITY}

The exhaust velocity was calculated from an approximate onedimensional model using the area normal to the duct centerline as the flow area and assuming the duct effluent to be perfectly mixed at the exit plane. Mixing is an important consideration as the duct downstream of the steamejector nozzles consisted of a straight mixing section only 5 diameters in length, followed by a 45-degree elbow. The jet direction was always assumed to be 38 degrees with the horizontal. This angle was determined from photographs of the plume from many previous model tests, taken when the exit Mach number was near unity. The actual situation is probably more complicated than this approximate model: the exit velocity profile is skewed and the flow area is reduced by the rotation in the elbow. 
IV. EXPERIMENTAL PROCEDURE

Gaseous hydrogen, steam, and miscellaneous other gases in trace amounts over a wide range of mixtures were expelled at large kinetic energies. Because of the difficulty of obtaining exactly the predicted exit velocity for any given test, i.e., the gas flow and temperature could not be regulated exactly, the microphone system ranges were selected for each test on the basis of both experience and theoretical calculations.

The XE tests were conducted both at night and during the day. If the test could not be completed during daylight it was completed during the night. Motion pictures and still photographs were taken. Figure 8 shows a photograph of the exhaust plume at a time when the plume composition was $100 \%$ steam. For convenience the arrowhead shown in the photograph is about $100 \mathrm{ft}$ away from ETS-1.

The method of determining the mechanical and thermal-to-acoustic power conversion efficiencies for burning jets used in this investigation was to consider the sound pressure spectrum as composed of a typical nonburning gas jet component plus an additional contribution in the lower frequencies caused by combustion. Because the portion ascribed to jet noise and the mechanical power was known, the mechanical-to-acoustic power conversion efficiency was determined for a number of tests and then averaged. This average was then assumed fixed for all tests, and equation (2) was solved to obtain the therma1-to-acoustic power conversion efficiency.

The test data could also be utilized to obtain new correlations for both acoustic efficiency and directivity index. This investigation would, however, involve time consuming trial-and-error cross-correlation studies because of the limited number of microphones and the sensitivity of the results to an assumed directivity index. 


\section{A. MICROPHONE LOCATIONS}

The locations of the microphones are summarized below:

\section{MICROPHONE LOCATIONS}

\begin{tabular}{|c|c|c|c|c|c|c|c|}
\hline \multicolumn{2}{|c|}{$\begin{array}{c}\begin{array}{c}\text { Microphone } \\
\text { Number }\end{array} \\
\end{array}$} & Location* & $\begin{array}{l}X \\
f t \\
\end{array}$ & $\begin{array}{c}\text { Coordina } \\
\mathrm{Y} \\
\mathrm{ft} \\
\end{array}$ & $\begin{array}{l}Z \\
\mathrm{ft} \\
\end{array}$ & $\begin{array}{c}\text { Distance*****} \\
\mathrm{ft}\end{array}$ & $\begin{array}{c}\text { Angle } * * * * \\
\text { Degree } \\
\end{array}$ \\
\hline \multicolumn{2}{|c|}{113} & $\mathrm{~N}$ & 0 & 0 & 25.5 & 23.1 & 48.5 \\
\hline \multicolumn{2}{|c|}{114} & $\mathrm{~F}$ & 283. & 283. & 60.5 & 386.3 & 128 \\
\hline \multicolumn{2}{|c|}{115} & $\mathrm{~N}$ & -23.3 & 0 & 125. & 115.7 & 97 \\
\hline \multicolumn{2}{|c|}{116} & $\mathrm{~N}$ & 0 & 13.5 & 6.1 & 32.2 & 40.4 \\
\hline \multicolumn{8}{|c|}{ * $\quad \mathrm{N}$ denotes near field. $F$ denotes far field. } \\
\hline \multicolumn{8}{|c|}{ ** Measured from the microphone to the calculated center of sound. } \\
\hline \multicolumn{8}{|c|}{$\begin{array}{l}\text { *** Center of sound location estimated for duct-exit conditions of Test } 5 \mathrm{C} \text {, } \\
\text { Table 1, CRT } 38930 \mathrm{sec} \text {. }\end{array}$} \\
\hline$* * * *$ & $\begin{array}{l}\text { Meas } \\
\text { exhe }\end{array}$ & $\begin{array}{l}\text { d from } t \\
t-j e t \text { dir }\end{array}$ & $\begin{array}{l}\text { forwa } \\
\text { tion. }\end{array}$ & end of & ctiti & rocket having & he same \\
\hline
\end{tabular}

A complete derivation of the equations and a list of the assumptions is included in Appendix ${ }^{(1)}$.

B. CONTRIBUTION OF HYDROGEN COMBUSTION TO THE SOUND PRESSURE

Tests with steam only, and with steam and varying quantities of hot or cold hydrogen were conducted to permit an indirect calculation of the contributions of hydrogen combustion to the overall noise. The conclusions of previous investigations have varied on the significance of this contribution; this is caused by the fact that all the important parameters for burning noise are not measured or calculated in a typical rocket firing. It would be expected that the Froude number, the heat of combustion of the fuel, 
extent of dilution with non-combustibles (i.e., the mol fraction of inert gases), and the duct-exit Mach number are the important parameters.

The combustion contribution was determined by extrapolation of nonburning sound pressure levels from these and other relevant tests and comparison with sound pressure levels when there was combustion at the same mechanical power levels. Figure 8 illustrates the relative scale of the plume and duct size. This photograph was taken several years ago of a steamonly jet to study the duct performance. The June meteorological data for the run days are included in Table 5.

Prior to testing, the sound recording equipment was calibrated as described whereas the gas flow, pressure and temperature measuring equipment were calibrated with a series of electrical calibrations at $20,40,60$, and 80 percent of full scale. Cameras were operated for a few seconds to determine if the film transport mechanisms were operating as required. Following each test all calibrations were repeated, if time permitted.

Each test was initiated by a pre-operational phase during which data systems, communications, valves, emergency systems, etc. were checked. The steam generators were then started and the engine tests followed. The NES was then shutdown and emergency systems secured. Calibration of the data system followed each test. Instrument ranges are presented in Table 3. 


\section{Local Climatological Data}
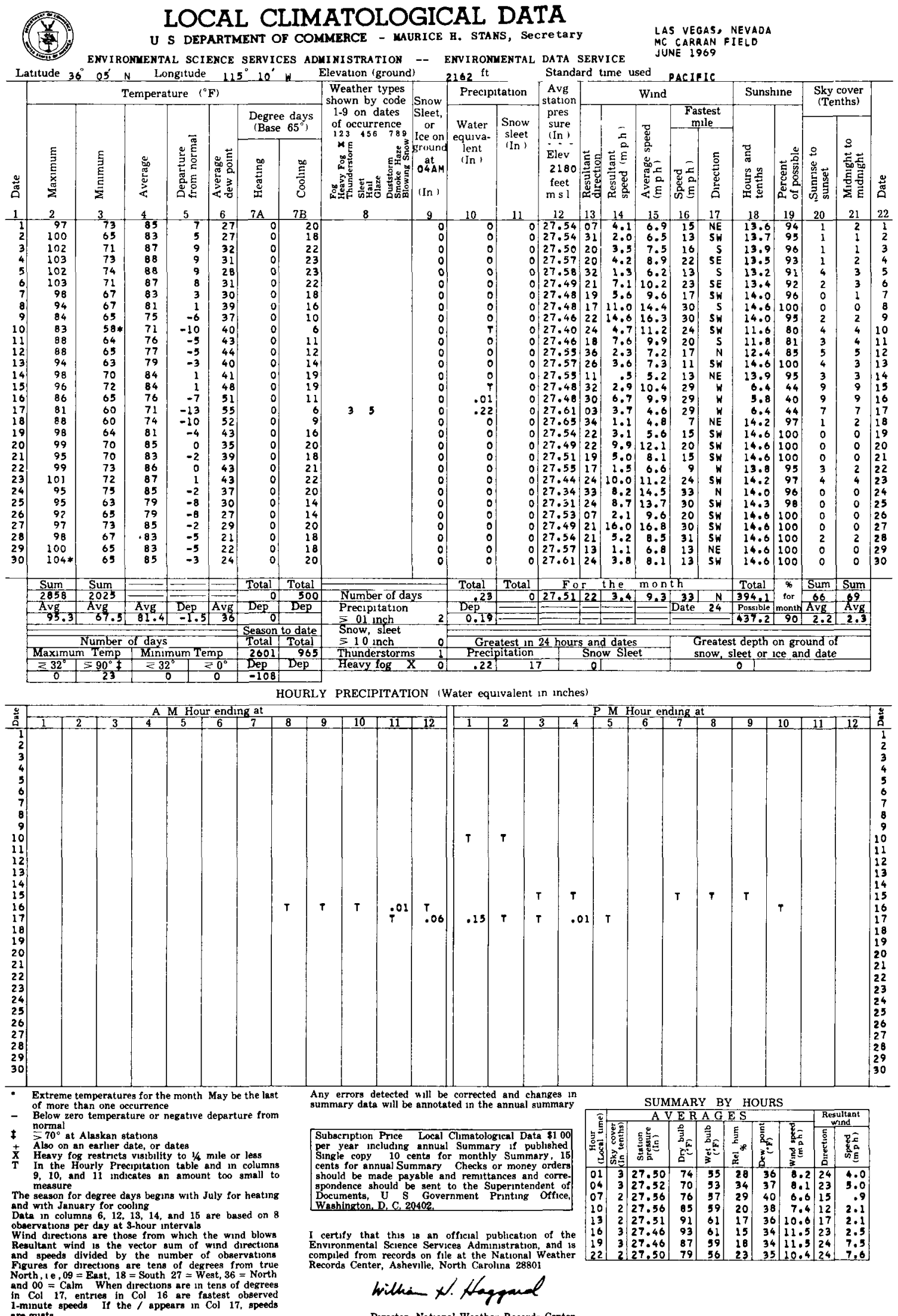

Director, Nationa! Weather Records Center 
TABLE 5 (continued)

Local Climatological Data

OBSERVATIONS AT 3-HOUR INTERVALS

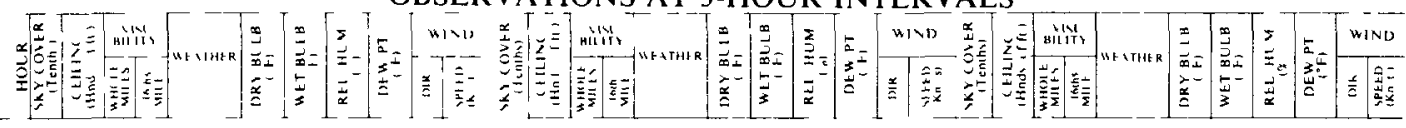

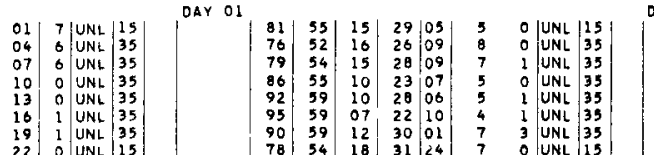

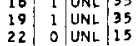

Dar o.

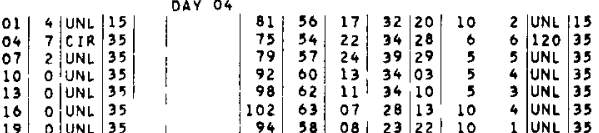

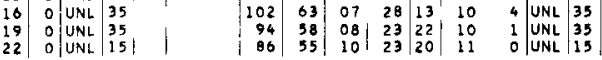

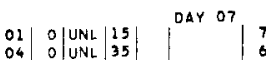

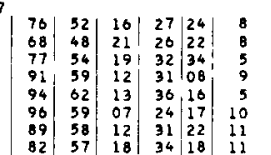

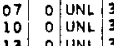

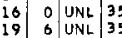

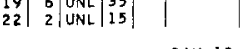

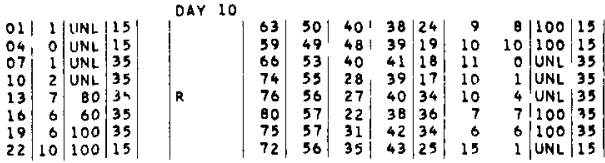

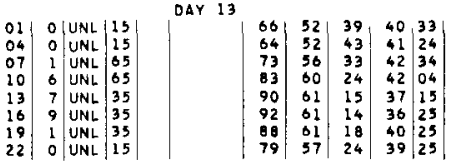

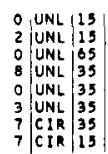

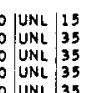

: UNL

\begin{tabular}{ll|l} 
UNL & 35 \\
UNL & 35 \\
\hline
\end{tabular}

U UNL

DAY 02

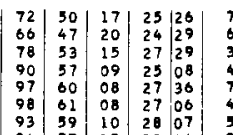

\begin{tabular}{l|l|l|l|l|l|}
0 & UNL & 15 \\
0 & UNL & 35 \\
1 & UNL & 35 \\
0 & UNL & 35 \\
0 & UNL & 35 \\
2 & UNL & 35 \\
4 & UNL & 35 \\
2 & UNL & 15 \\
\hline
\end{tabular}

DAY 05

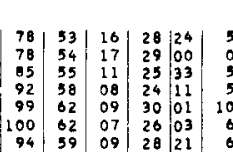

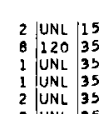

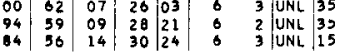

Day or

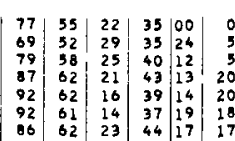

\begin{tabular}{l|l|l|}
0 & UNL & 15 \\
0 & UNL & 15 \\
1 & UNL & 35 \\
0 & UNL & 35 \\
1 & UNL & 35 \\
2 & UNL & 35 \\
0 & UNL & 35
\end{tabular}

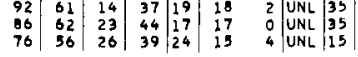

DAY 11

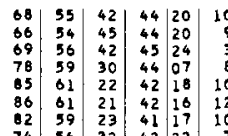

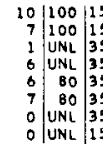

DAY 14

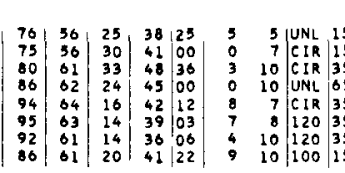

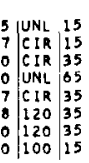

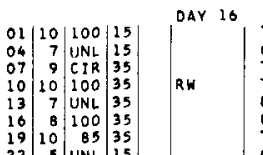

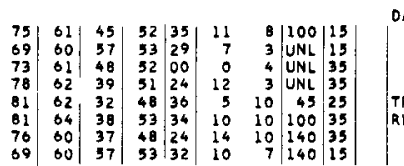

DYY 17
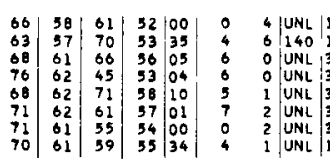

\begin{tabular}{l|l|l|}
4 & UNL & 15 \\
6 & 140 & 25 \\
0 & $U N L$ & 35 \\
0 & UNL & 35 \\
1 & UNL & 35 \\
2 & UNL & 35 \\
2 & UNL & 35 \\
1 & UNL & 15
\end{tabular}

DAY OS

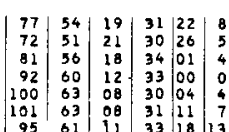

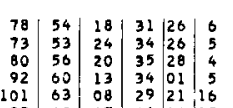

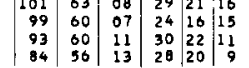

daY og

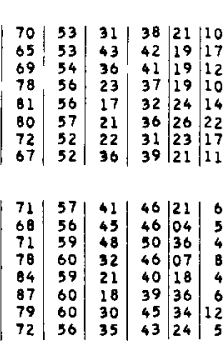

DAY 15

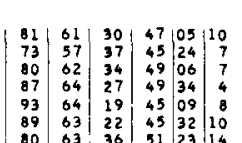

oar 18

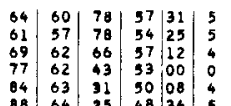

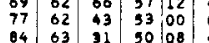

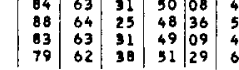

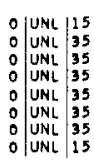

Dar 21

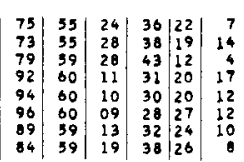

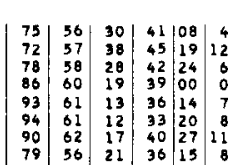

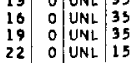

01 2 IUNL 15 I DAY 22

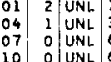

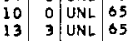

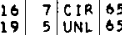

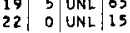

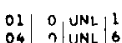

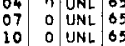

13.0 UNL 35

\begin{tabular}{l|l|l|l|l|l}
16 & 0 & $U N L$ & 20 \\
19 & 0 & $U N L$ & 20 \\
22 & 0 & $U N L$ & 15
\end{tabular}

$01 \mid 1$ UNL 13

\begin{tabular}{l|l|l|l|l|}
01 & 1 & UNL & 15 \\
04 & 7 & UNL & 35 \\
07 & 8 & UNL & 35 \\
\hline & 13 & 0 & UNL & 35
\end{tabular}

\begin{tabular}{lllll}
10 & 8 & $U N L$ & 35 \\
13 & 0 & $U N L$ & 35 \\
\hline$N N$ & 35 \\
19 & 0 & $U N L$ & 35
\end{tabular}

130 年

\begin{tabular}{ll|l|l|l|}
19 & 0 & UNL & 35 \\
22 & 0 & UNL & 15 \\
\end{tabular}
Dar 19

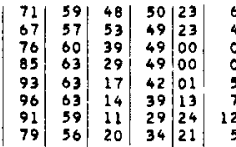

$\mid \begin{aligned} & 76 \\ & 73 \\ & 79 \\ & 38 \\ & 97 \\ & 97 \\ & 88 \\ & 89\end{aligned}$

Dar 25

$\mid$\begin{tabular}{l|l}
74 \\
68 \\
78 \\
86 \\
92 \\
93 \\
83 \\
80 \\
80
\end{tabular}

OAY $\angle B$

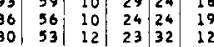

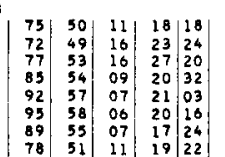

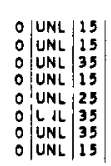

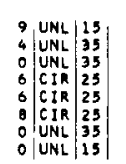

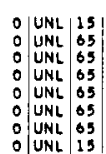

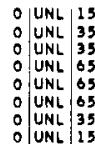

DAY 23

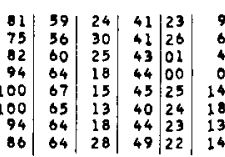

DAY 26

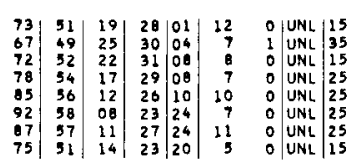

oar 29

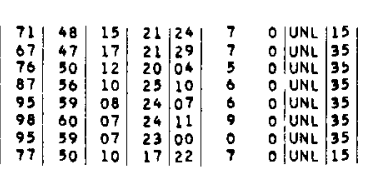

oar 24

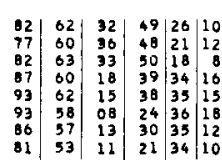

DAY 23

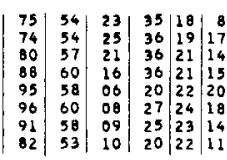

Dar 30

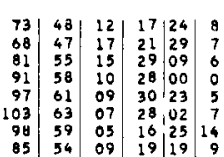

NOTES

(EILING COLUMNUNL indicates an unlımited celling
CIR undicates a crrofform
cloud celling of unktown WEATHER COLUMN

i Thrnado $Q$ Squall

RW Rain shower $\begin{array}{ll}\mathrm{L} & \text { Drizzle } \\ \mathrm{ZL} & \text { Freezing drizzle }\end{array}$ SP Snow pellets SW Snow showers A Sleet AP Small hai GF Grofog fog BD
BN Blowing dust
BS Blowing sand
BS lowing snow BS Blowing snow
BY Blowing sprdy $\begin{array}{ll}\mathrm{K} & \text { Smoke } \\ \mathrm{H} & \text { Hdre } \\ \mathrm{D} & \text { Dust }\end{array}$ WIND COLUMNS Directions are those from
which the wind blows ind cded in tens of degrees
from true North 1 e 09

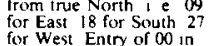
the direction column ind Speed is expressed in knots
multiply bv 15 to convert

ADDITIONAL DATA

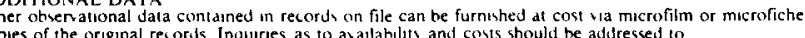

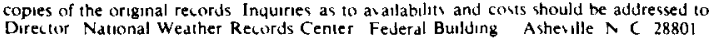

STATION LAS VEgAS NEVADA

YEAF \& MONTH 6906 
V. RESULTS OF DATA ANALYSIS

The recorded data were of necessity not in final form. For example, gas pressure was recorded on magnetic tapes and oscillographs as percent of full scale, and sound pressure was recorded on magnetic tape. These raw data were reduced to meaningful engineering units after each test. The following parameters were calculated: gas flow rate, molecular weight, temperature, velocity and Mach number, sound pressure and frequency, and heat radiation from the plume, by using the methods described in Appendices of Reference ( 1 ).

\section{A. FLOW PARAMETERS}

The flow parameters that were determined for each test, or at selected times during a given test when the test involved a flow ramp, are given above (see also Tables 1 and 4).

\section{B. ACOUSTIC EFFICIENCY}

One generally accepted method of predicting sound pressure levels for jets is to determine the jet mechanical power, estimate the acoustic powerconversion efficiency, and then calculate the sound pressure level. This method is successful because the efficiency changes less than any of the other jet parameters. The theoretical model that is the basis for this method is designated herein as the mechanical model. It has the disadvantage in that it ignores the contribution of burning to the noise. Another method, which is more complex, is to determine the jet mechanical and thermal power, estimate the mechanical and thermal power-conversion efficiency and then calculate the sound pressure level. The corresponding designation is "Thermal mechanical model."

The data obtained in these tests have been evaluated by calculating the jet mechanical power, overall acoustic power level, acoustic powerconversion efficiency, jet thermal power, and mechanical and thermal 
power-conversion efficiencies. The results of this analysis are listed below. A11 test times were selected from runs when the flow of hydrogen gas was significant, i.e., the plume shape and velocity were momentum rather than buoyancy controlled.

The acoustic conversion efficiencies were calculated from the measured-sound pressure levels for all scale-model and XE tests. The results of the analysis for typical cases of both test series are shown below:

\section{ACOUSTIC CONVERSION EFFICIENCIES, SELECTED SCALE-MODEL TESTS}

$\begin{array}{lllllllll}\text { Test No. } & \text { A2 } & \text { A2 } & \text { A5 } & \text { A5 } & \text { A6 } & \text { A6 } & \text { A17 } & \text { A17 } \\ \text { Microphone(s) } & 5 & \text { A11 } & 5 & \text { A11 } & \text { A11 } & \text { A11 } & \text { A11 } & \text { A11 } \\ \text { Time, sec } & 10 & 10 & 9 & 9 & 67 & 92 & 92 & 108 \\ \text { WMJET, megawatts } & 2.03 & 2.03 & 2.79 & 2.79 & 1.204 & 1.204 & 0.640 & 0.207 \\ \text { OAPW, kilowatts } & 8.12 & 11.17 & 10.32 & 9.49 & 4.70 & 5.54 & 2.94 & .869 \\ \text { OAPWL, db re 10 } & 159.3 & 170.8 & 170.2 & 159.7 & 166.6 & 167.4 & 164.7 & 169.4 \\ n \text {,\% watt } & 0.40 & 0.58 & 0.37 & 0.34 & 0.39 & 0.46 & 0.46 & 0.42 \\ \text { nM, \% } & 0.20 & 0.20 & 0.20 & 0.20 & 0.20 & 0.20 & 0.20 & 0.20 \\ n \mathrm{TH}, \% & .0023 & .0048 & .0027 & .0022 & .0017 & .0031 & .0024 & .0013\end{array}$

The average value of $\eta$ for all scale-model tests is $0.43 \%$ with a standard deviation of $0.074 \%$. Similarly, the average value of $\mathrm{nTH}$ and its standard deviation are 0.0023 and $0.00099 \%$, respectively. A constant value of $0.20 \%$ for $n M$ was assumed for al1 scale-model tests based on the data of Manhart ${ }^{(2)}$. 


\section{ACOUSTIC CONVERSION EFFICIENCIES, SELECTED ENGINE TESTS (XE)}

\begin{tabular}{|c|c|c|c|c|c|c|}
\hline Test No. EP- & 3 & 3 & $5 \mathrm{C}$ & $5 C$ & $5 C$ & $6 \mathrm{~A}$ \\
\hline Time, sec & 54625 & 54990 & 38800 & 38930 & 39200 & 44320 \\
\hline WMJET, megawatts & 0.714 & 16.8 & 30.3 & 191 & 10.5 & 0.843 \\
\hline OAPW, kilowatts & 6.03 & 111.5 & 201 & 1077 & 105.9 & 5.37 \\
\hline OAPWL, $d b$ re $10^{-13}$ watt & 167.8 & 180.4 & 183.0 & 190.3 & 180.2 & 167.3 \\
\hline$n, \%$ & 0.844 & 0.66 & 0.66 & 0.56 & 0.99 & 0.64 \\
\hline$n M, \%$ & 0.18 & 0.33 & 0.42 & 0.50 & 0.55 & 0.38 \\
\hline$n \mathrm{TH}, \%$ & 0.0023 & 0.0023 & 0.0023 & 0.0023 & 0.0023 & 0.0023 \\
\hline
\end{tabular}

For all tests, the average values of $\eta$ and $\eta M$ are 0.73 and $0.32 \%$ respectively, with standard deviations of 0.254 and $0.181 \%$. The heating value of hydrogen was taken as $60,000 \mathrm{Btu} / 1 \mathrm{~b}$.

\section{Comparison of Acoustic Models}

Two theoretical models have been described and the corresponding results of the data analysis presented. The results are summarized below:

\section{COMPARISON OF ACOUSTIC MODELS}

\begin{tabular}{|c|c|c|c|c|}
\hline Test Series & Gas & $n_{2} \%$ & $\underline{\mathrm{nTH}}, \%$ & $\mathrm{nM}, \%$ \\
\hline Engine series (XE) & Steam $+\mathrm{GH}_{2}$ & 0.73 & 0.0023 & 0.32 \\
\hline Scale Model (1) & $\mathrm{GH}_{2}$ & 0.43 & 0.0023 & 0.20 \\
\hline Scale Model (1) & $\mathrm{GHe}$ & 0.50 & --- & -- \\
\hline
\end{tabular}

The calculated standard deviations from experiments for the mechanical and thermal-mechanical models are 0.254 and $0.181 \%$, respectively. This indicates that the acoustic prediction should be improved if the second theoretical model is used, i.e., the contribution of the burning hydrogen to the noise is considered as an additive term to the mechanical contribution. 
Evaluation of the test results also indicates that for a duct using hydrogen gas mixtures, a thermal-to-acoustic power conversion efficiency of $0.0023 \%$, as calculated by Ortega ${ }^{(10)}$, would appear to be a valid number. The calculated mechanical-to-total acoustic power-conversion efficiency is in substantial agreement with the results of other investigations such as that done by Manhart ${ }^{(2)}$.

\section{OVERALL SOUND PRESSURE LEVEL}

The most important information obtained from this or any similar test series is the overall sound pressure level (OASPL) because the structural integrity of the inerting wall is influenced by this parameter. Because jet noise is broadband in character, it is not necessary to analyze the noise in any great detail; overall sound pressure levels and octave-band analysis, described later, are adequate. The overall sound pressure levels were determined by tape playback on a Bruel and Kjaer analyzer. Pretest and posttest calibrations were utilized to range the analyzer and to insure that calibration did not change during the test. Figure 9 shows typical overall sound pressure levels prior to full-power test 5C. Note that the duration of the test is important as the jet takes a finite time to reach steady-state.

Figure 10 shows the overall sound pressure levels at microphone 113 during full-power test 5C. The evaluation of differences in noise levels requires consideration of related performance parameters such as mechanical power, nozzle diameter, mass flow, velocity, density, directivity, and combustion level. Figures 11, 12 and 13 show similar data for microphones 114 , 115 , and 116 .

Sound pressure levels were determined for each microphone 16 times during the tests. The results of this study are presented in Table 6 . The ranges of all the instruments were limited so a procedure was utilized to prepare for each test; rough-order-of-magnitude sound pressure levels were predicted and the results used for ranging the instruments. 


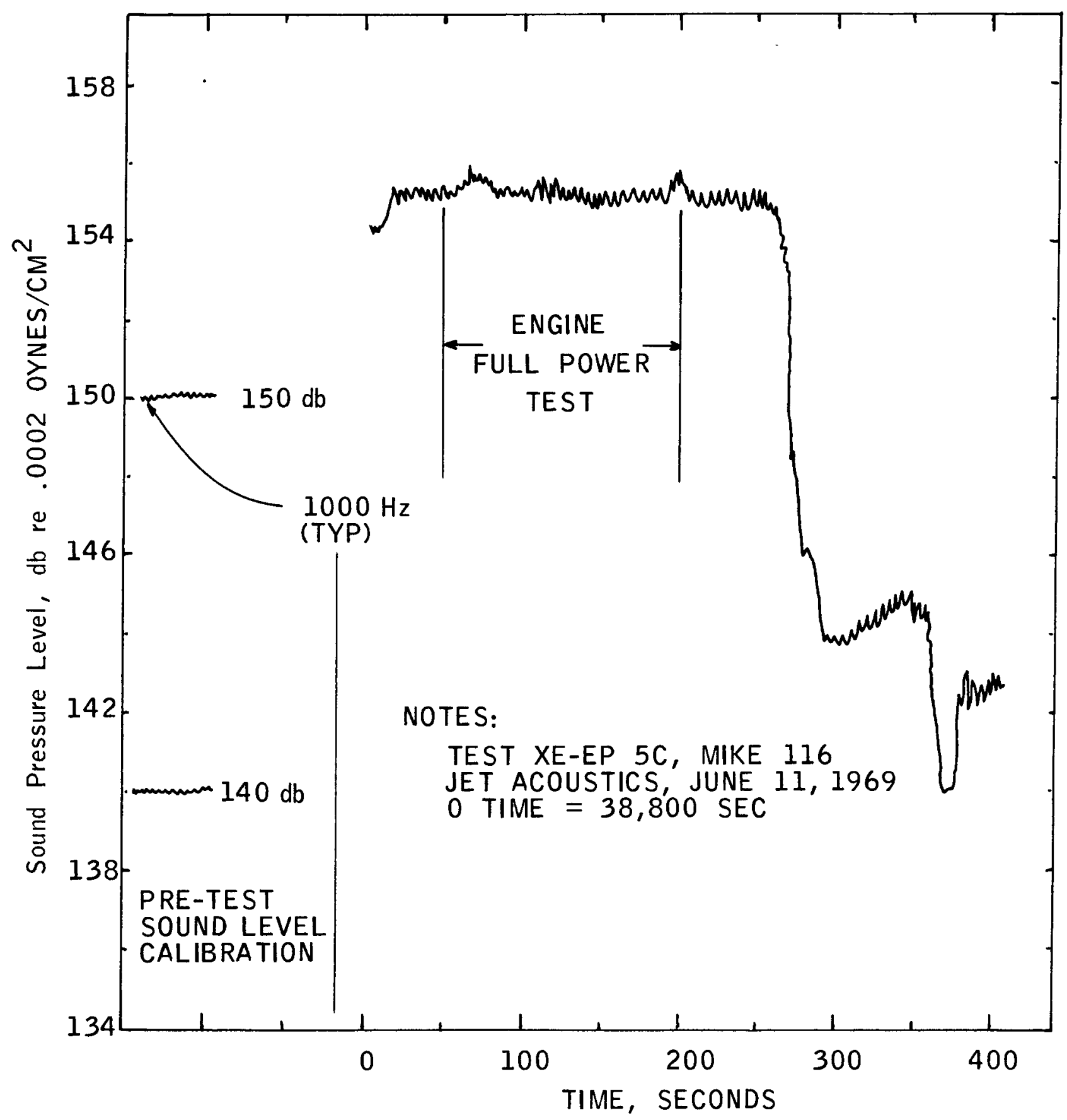

Figure 9 - Overal1 Sound Pressure Level, Microphone 116 


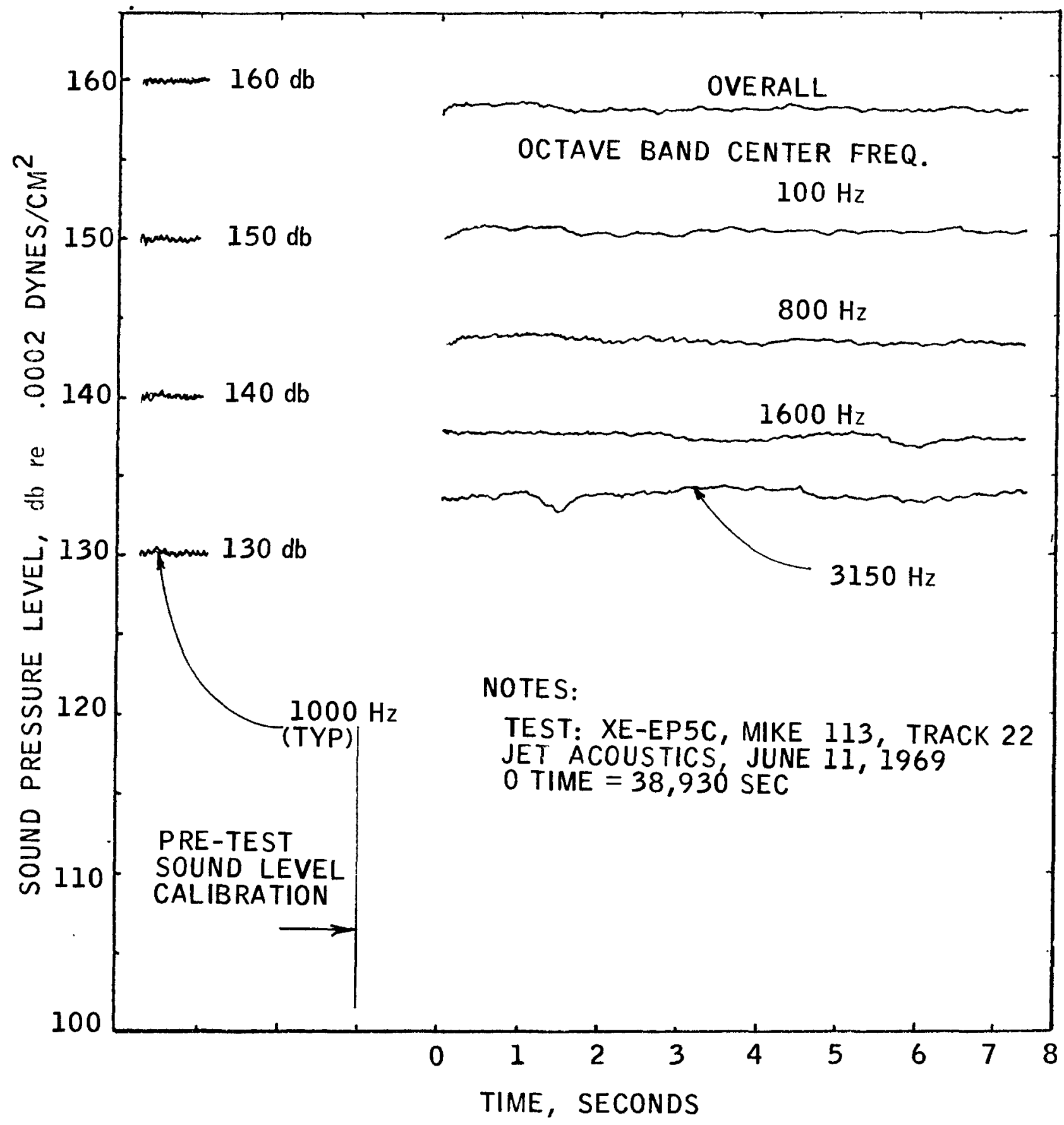

Figure 10 - Sound Spectra for Microphone 113 


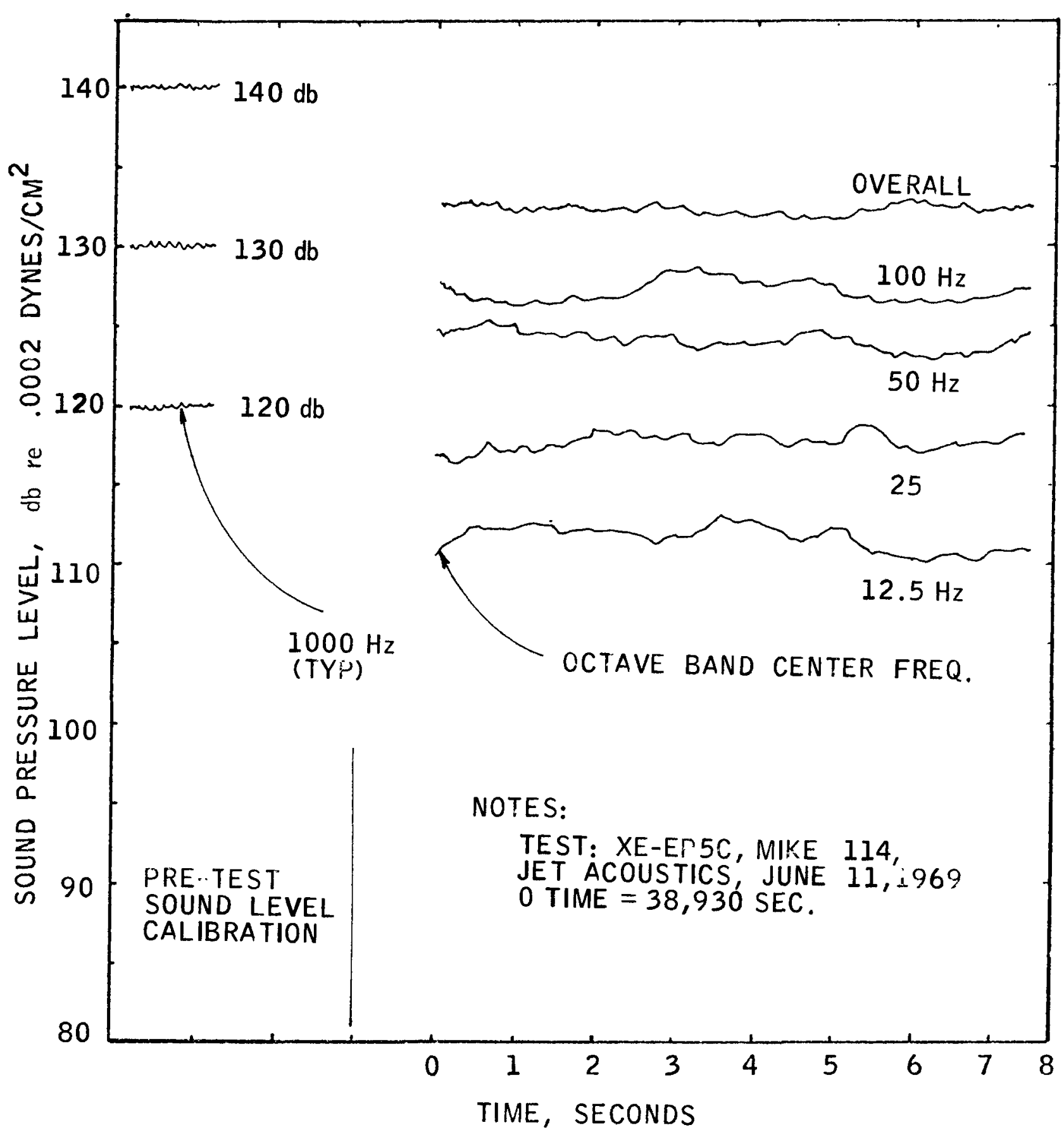

Figure 11 - Sound Spectra for Microphone 114 


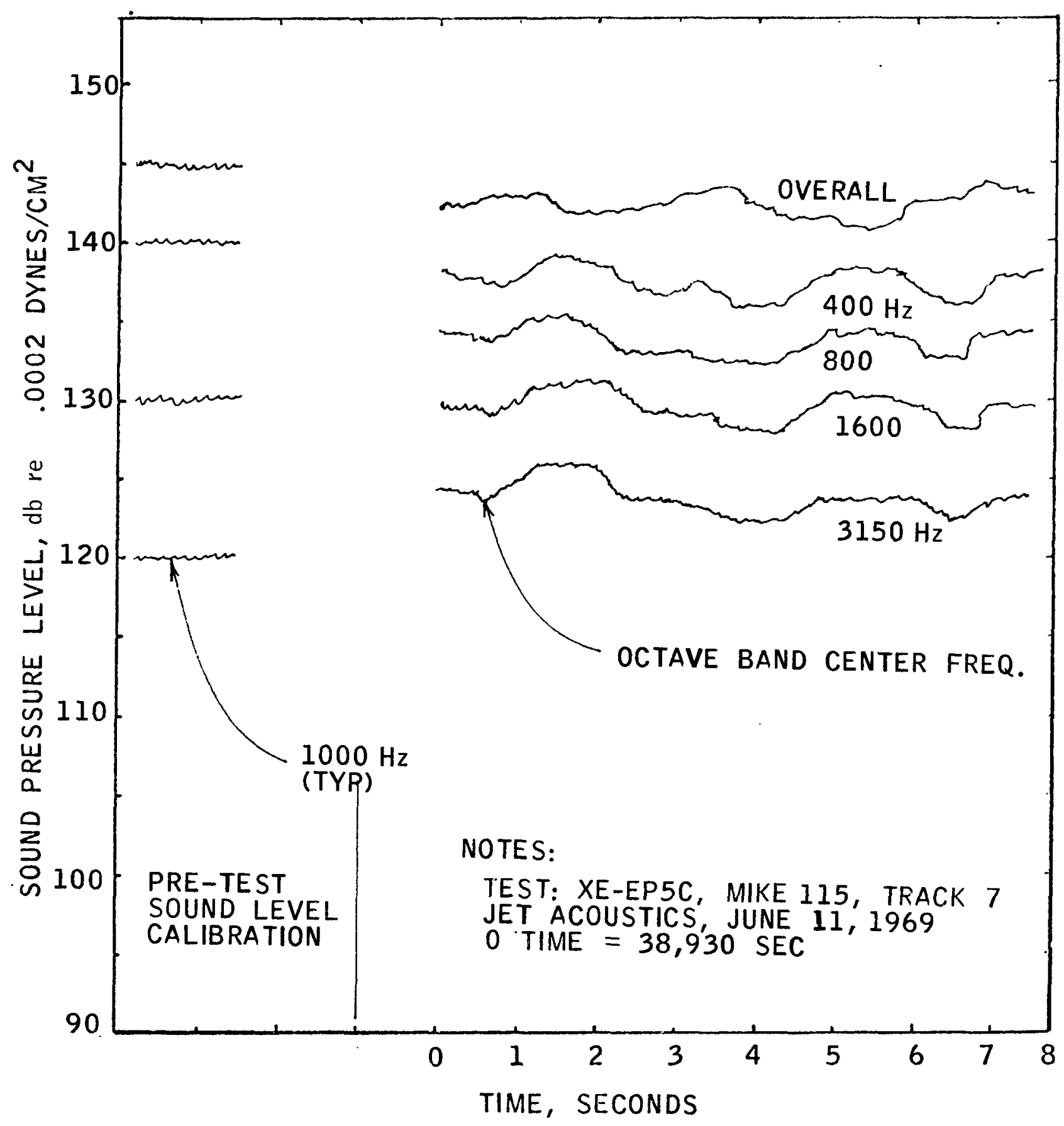

Figure 12 - Sound Spectra for Microphone 115 


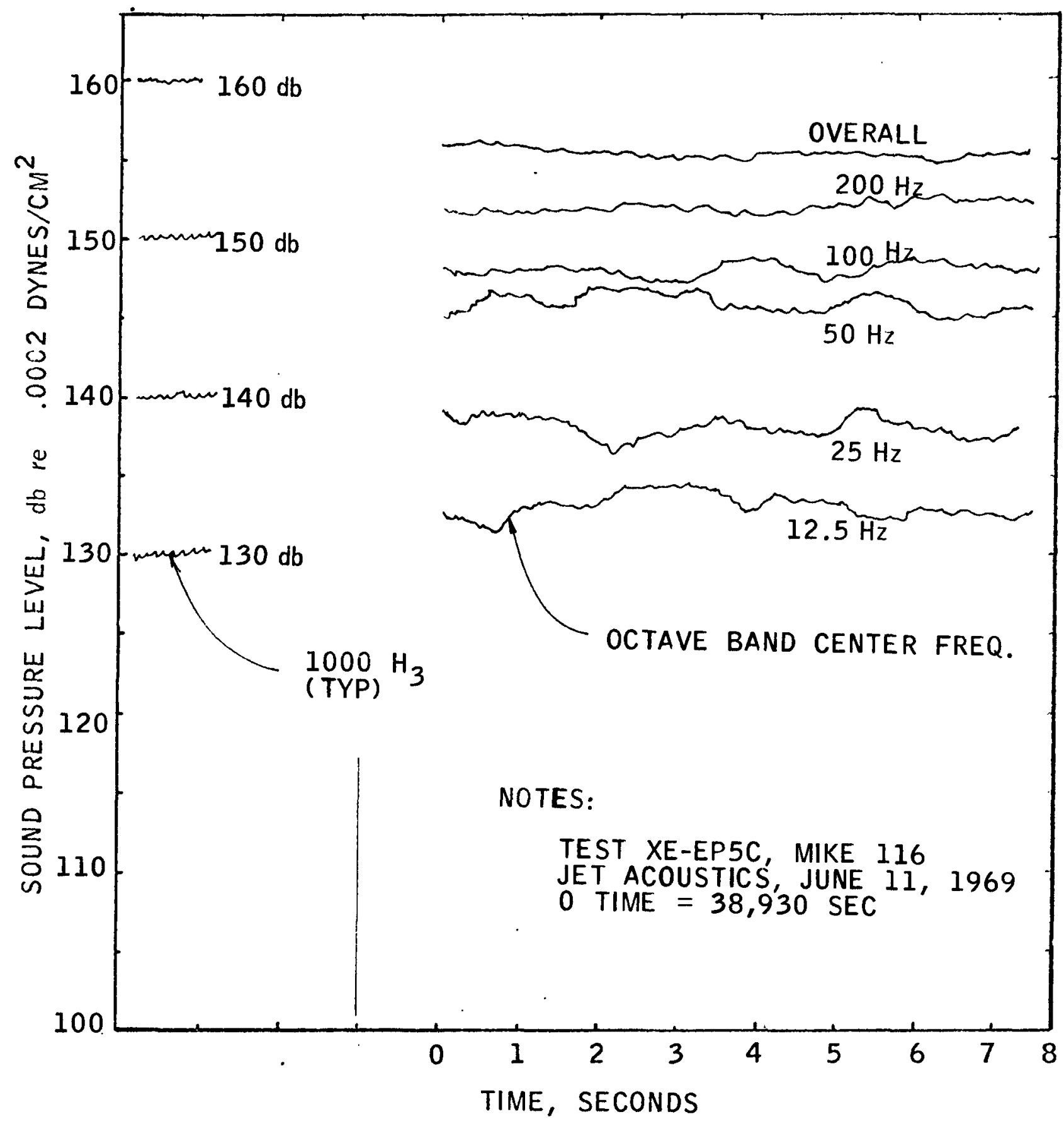

Figure 13 - Sound Spectra for Microphone 116 
TABLE 6

SOUND PRESSURE LEVELS
$\left(\mathrm{db}\right.$ re .0002 dynes $\left./ \mathrm{cm}^{2}\right)$

\begin{tabular}{|c|c|}
\hline $\begin{array}{c}\text { Cest } \\
\text { No. }\end{array}$ & $\begin{array}{l}\text { Time } \\
\text { sec. }\end{array}$ \\
\hline $2 \mathrm{~A}$ & 49270 \\
\hline $2 \mathrm{~A}$ & 49350 \\
\hline $2 \mathrm{~A}$ & 49450 \\
\hline $2 \mathrm{~A}$ & 49478 \\
\hline 3 & 54625 \\
\hline 3 & 54900 \\
\hline 3 & 54990 \\
\hline 3 & 55250 \\
\hline $5 \mathrm{C}$ & 38500 \\
\hline $5 \mathrm{C}$ & 38800 \\
\hline $5 C$ & 38930 \\
\hline $5 C$ & 39200 \\
\hline $6 \mathrm{~A}$ & 44320 \\
\hline $6 \mathrm{~A}$ & 44520 \\
\hline 9 & 59200 \\
\hline 9 & 39810 \\
\hline
\end{tabular}

\begin{tabular}{rrrrr}
\hline \multicolumn{5}{c}{ Microphone Number } \\
113 & 114 & 115 & 116 \\
134.5 & 112.5 & 114.4 & 125.5 \\
134.5 & 112.5 & 114.5 & 125.7 \\
140.0 & 118.5 & 121.5 & 139.5 \\
142.0 & 121.0 & 120.0 & 144.0 \\
132.0 & 109.5 & $*$ & 136.5 \\
151.5 & 123.0 & $*$ & 149.6 \\
147.0 & 118.5 & $*$ & 148.6 \\
140.5 & 112.5 & $*$ & 140.0 \\
137.0 & 112.0 & 116.0 & 138.0 \\
150.5 & 125.0 & 131.0 & 148.5 \\
158.0 & 132.4 & 142.0 & 156.2 \\
146.5 & $*$ & $*$ & 144.5 \\
132.5 & 108.5 & $*$ & 135.0 \\
142.5 & 116.5 & $*$ & 140.5 \\
134.5 & 112.0 & 114.0 & 135.0 \\
148.0 & 126.5 & 126.5 & 148.5
\end{tabular}

*electrical failure 
EP-2A tests, CRT $49270 \mathrm{sec}$ and $49350 \mathrm{sec}$, were primarily tests of a steam jet only as the engine was not operating. Note that the microphone readings are nearly identical for these two conditions as shown in Table 6 . The reproducibility of the microphone readings when only the steam jet was operating is one of the criteria for internal consistency of the data.

D. SPECTRAL DATA

Sound spectra are important characteristics of this or any noise source. For example, in structural analysis of the subject wall, the wall as an entity will have a resonant frequency, the wall frame will probably have a different resonant frequency, and each panel will have its own resonant frequency that may be different than that of adjacent panels. A given amount of energy at low, midrange, and high frequencies will have markedly different effects in terms of exciting the structure. The data process for obtaining spectra is described below.

A11 acoustic tapes were processed through the Bruel and $\mathrm{Kjaer}$ Graphic Leve1 Indicator to obtain OBSPL (Octave-Band Sound Pressure Levels). The bands chosen for analysis were 12.5, 25, 50, 100, 200, 400, 800, 1600, 3150,6300 , and $12,500 \mathrm{~Hz}$. This narrow-band analysis was done by using Bruel and $\mathrm{Kjaer}$ octave-band filters that have a relatively sharp cutoff, $13 \mathrm{db}$ per $1 / 3$ octave. The results of the study for typical test conditions are shown in Figures 10 through 13. Note that there is a peak from about 100 to $400 \mathrm{~Hz}$ band. This pattern is typical of jet noise from rockets and large turbojet engines.

Experience gained from the scale-model tests showed that when the jet had a large thermal-energy content (amount of burning hydrogen) there were peaks at about 100 and $1600 \mathrm{~Hz}$. It was suggested that the bi-modal spectra was caused by a large energy noise contribution at $1600 \mathrm{~Hz}$ by jet turbulence

* Because the contribution of the last two bands was insignificant, these were later eliminated from the study. 
and another at $100 \mathrm{~Hz}$ by combustion. However, it appears that there is no such bi-modal shape to the spectra here. The explanation suggested is that the combustion noise spectra is not sensitive to jet diameter but that the turbulence noise is. The turbulence energy is now in the 100 to $400 \mathrm{~Hz}$ band, and so the spectra show only a typical broad noise resulting from both noise energy sources acting simultaneously.

Four large propane igniters were provided at the end of the NES duct to flare the hydrogen. All of the hydrogen plumes burned vigorously.

Figures 14 through 18 show the measured octave-band pressure levels for tests $2 \mathrm{~A}, 3,5 \mathrm{C}, 6 \mathrm{~A}$, and 9 . Note the broadband nature of the noise. The average sound pressure level over the range of frequencies of interest is only slightly less than the maximum.

The octave-band sound pressure spectra for air jets indicate about $9 \mathrm{db} /$ octave rol1-off below the frequency at which the sound-pressure peaks and about $4 \mathrm{db} /$ octave above this frequency, whereas for chemical rocket jets the equivalent values are about 4 and $2 \mathrm{db}$ respectively. Air-jet and helium-jet spectra are similar to the right-hand half of the hydrogen-jet spectra. Examination of the noise spectra from these tests shows a roll-off of about 5 and $2.5 \mathrm{db} /$ octave respectively. This agrees with data for chemical rockets.

\section{E. NEAR AND FAR FIELD LIMITS}

A preliminary estimate was made of the acoustic spectrum to determine the limits of the acoustic near and far fields for the jet tests. It was determined that a distance of $200 \mathrm{ft}$ would be sufficient to locate the microphones within the far field. Therefore, the far-field microphone was located more than $300 \mathrm{ft}$ away from the sound center to insure that far-field results would be obtained. Microphones 113, 115, and 116 were intended to obtain specific design data in the near field and were located near the jet source on the critical components of the stand. 


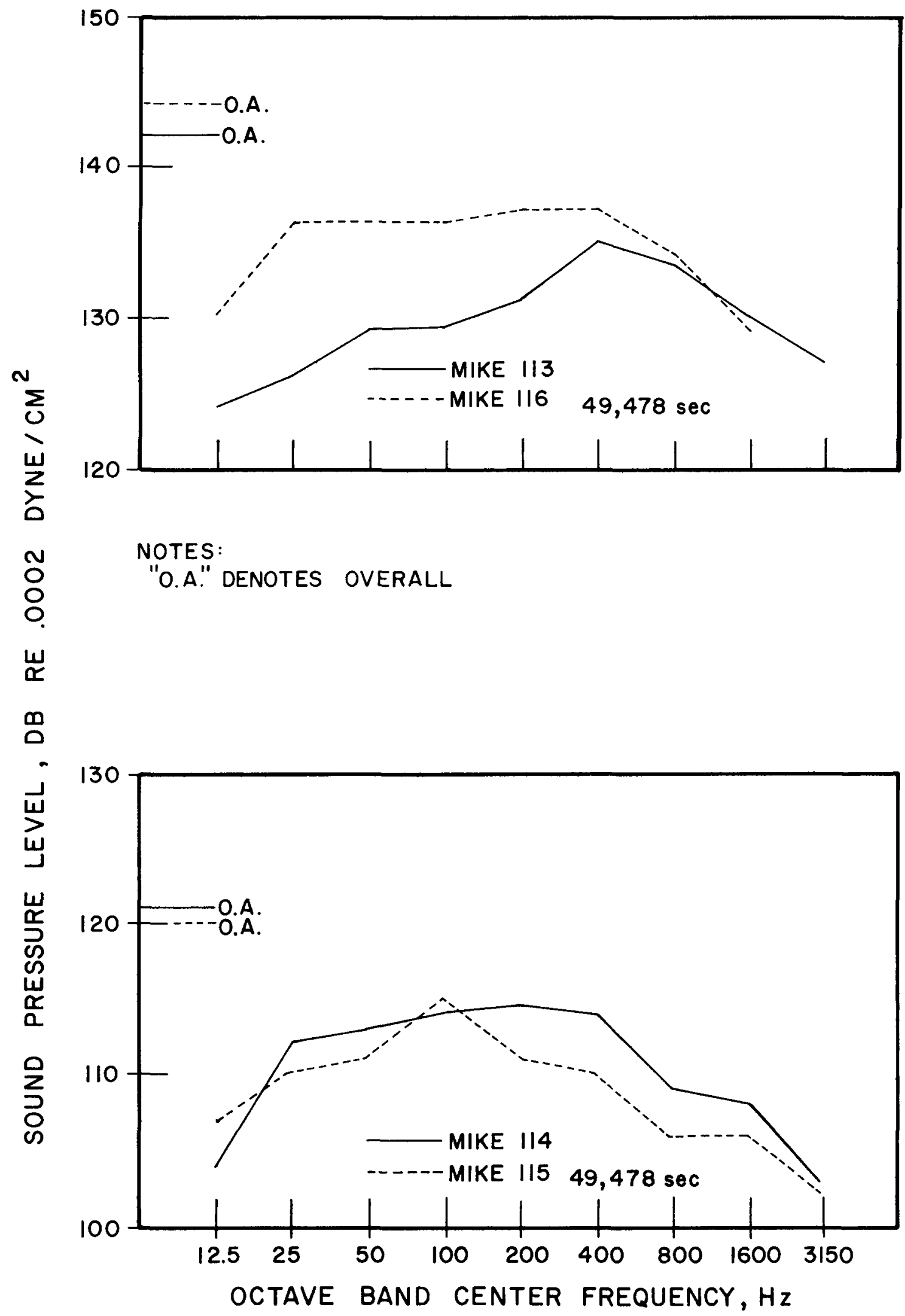

Figure 14 - Octave-Band Pressure Leve1, Test EP-2A 

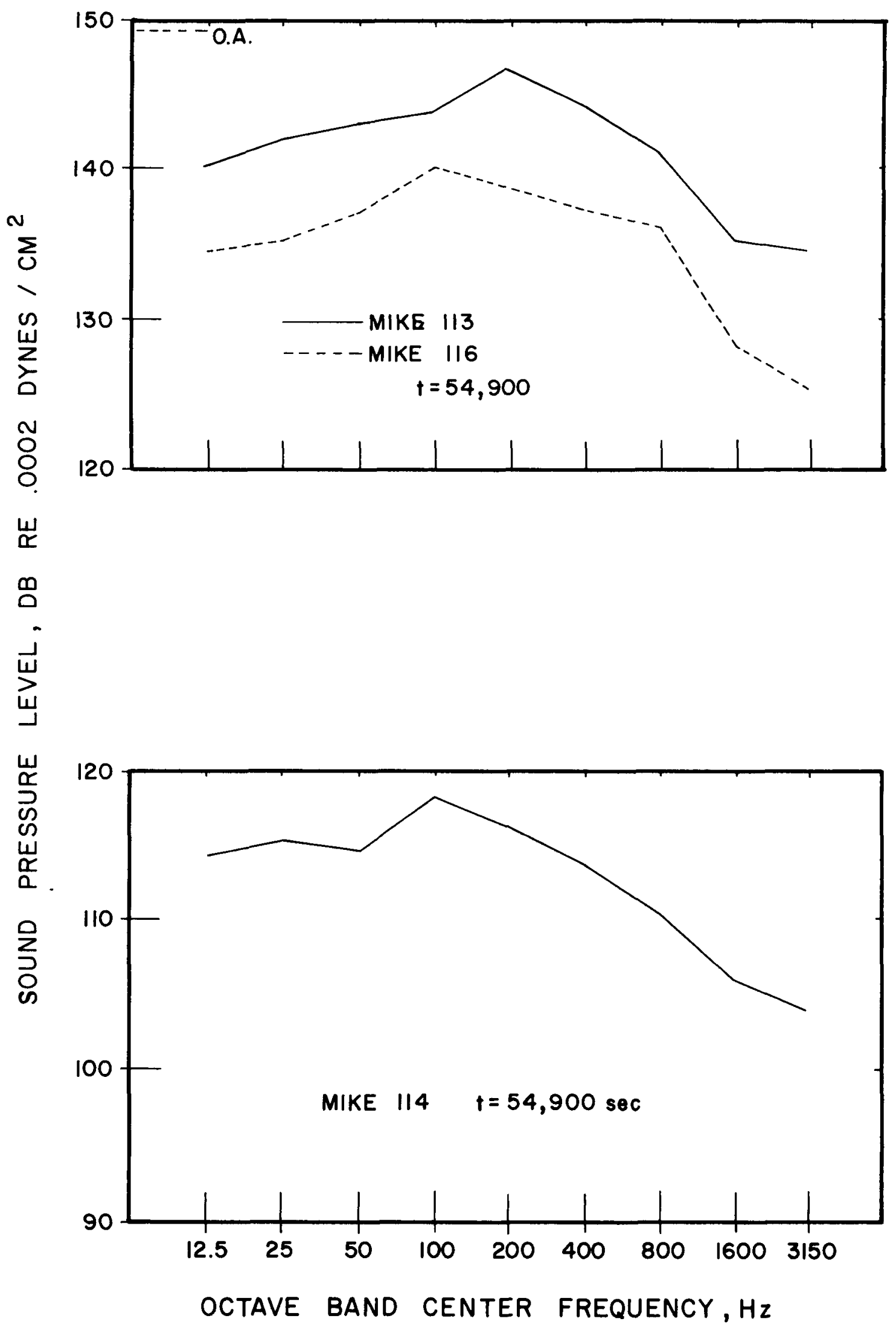

Figure 15 - Octave-Band Pressure Leve1, Test EP-3 


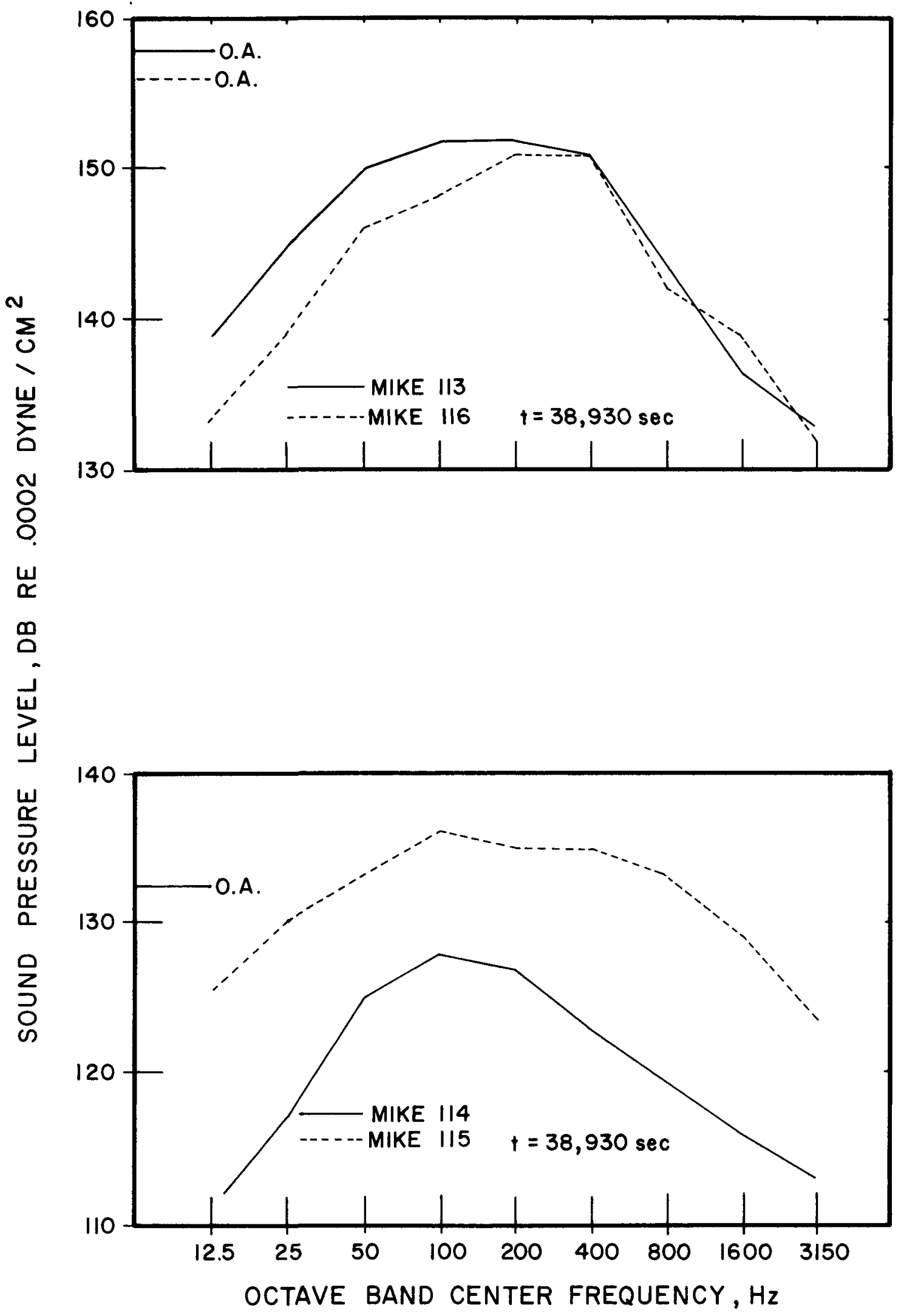

Figure 16 - Octave-Band Pressure Leve1, Test EP-5C 

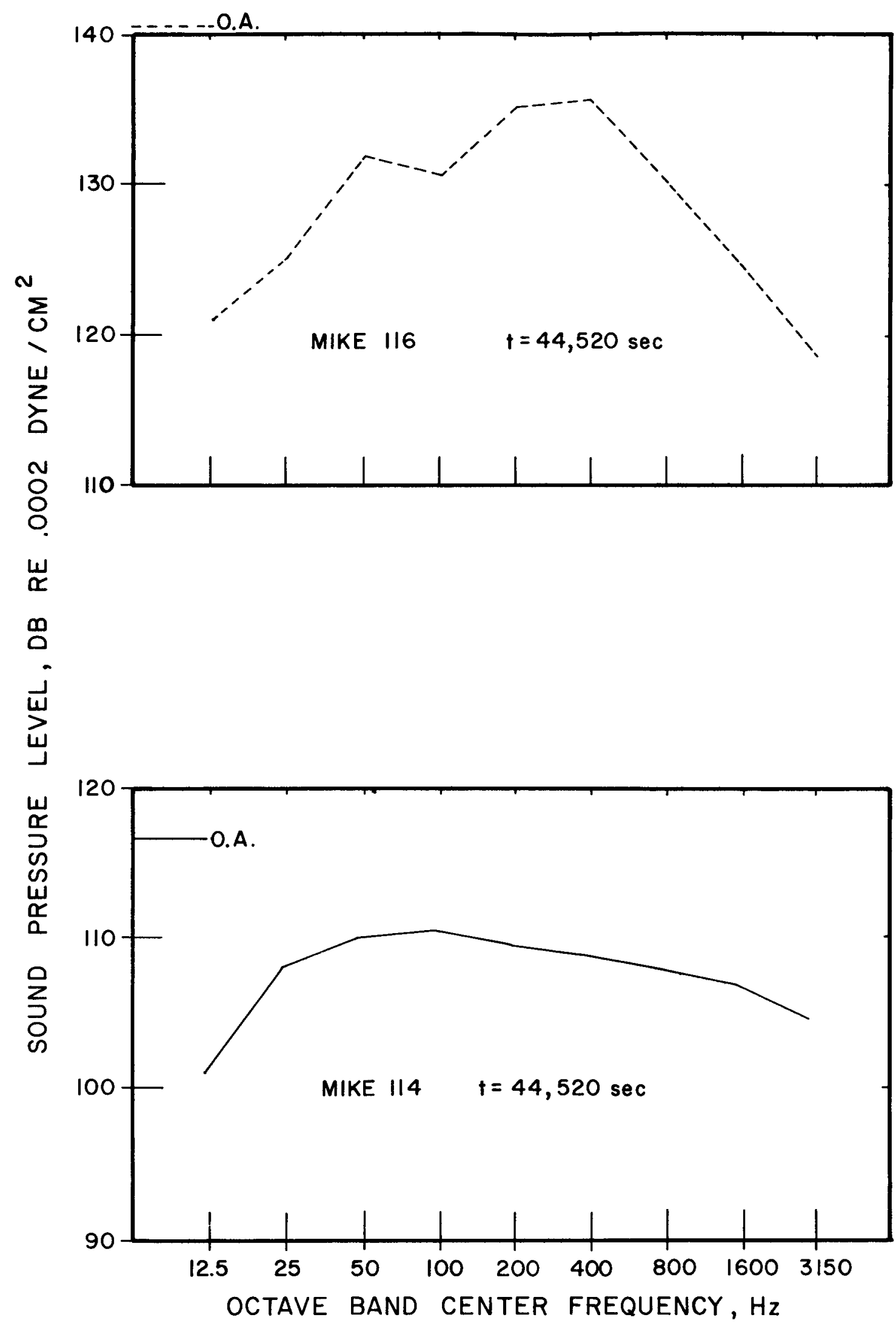

Figure 17 - Octave-Band Pressure Leve1, Test EP-6A 


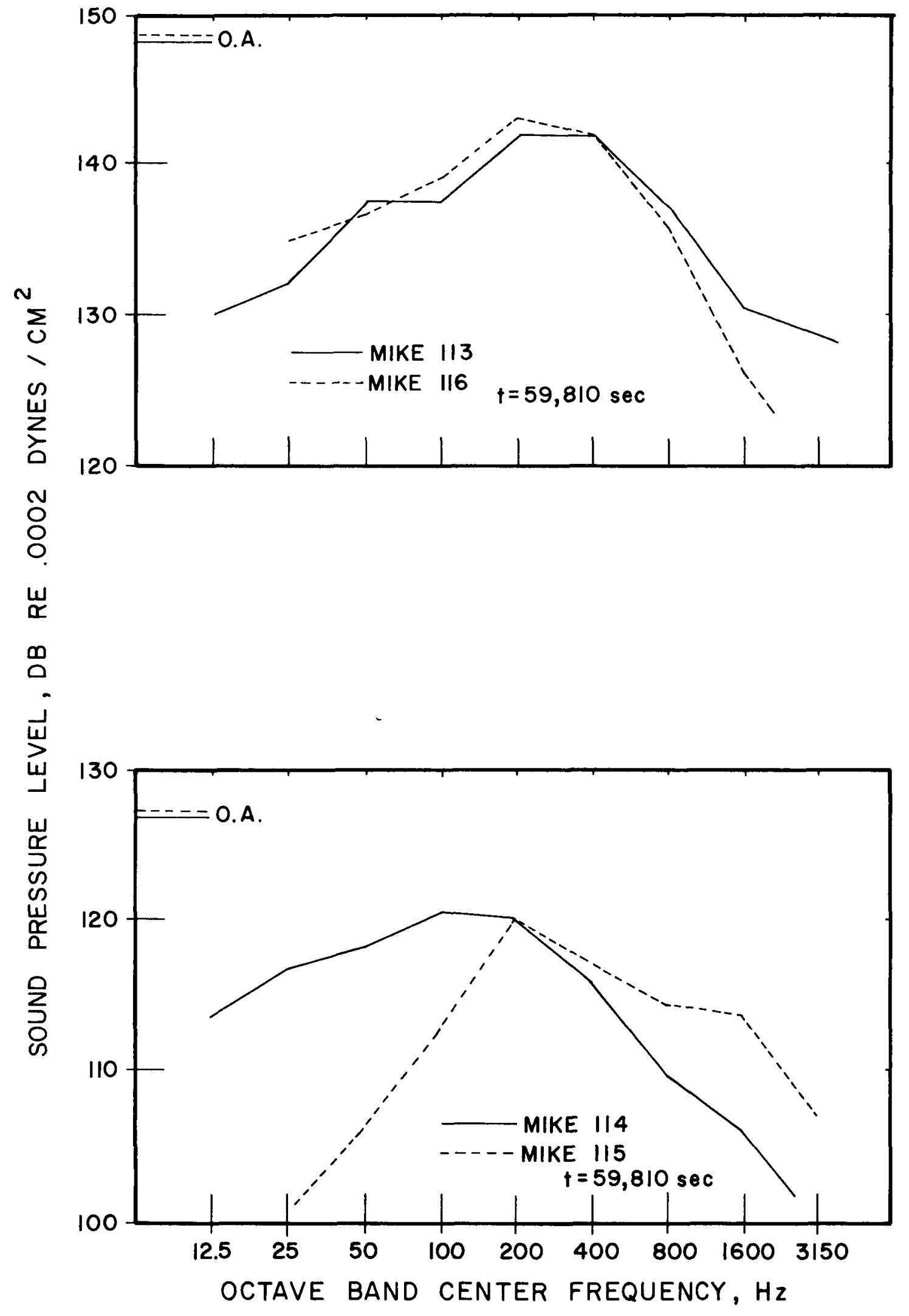

Figure 18 - Octave-Band Pressure Leve1, Test EP-9 


\section{F. PROBABLE ACCURACY}

The SPL (Sound Pressure Levels) and PWL (Sound Power Levels) presented in this report are subject to the following errors: electrical, visual, calibration, atmospheric, data reduction, and data processing. These are estimated to be as follows:

$\begin{array}{ll}\text { Electrical noise } & \pm 0.2 \mathrm{db} \\ \text { Visual reading } & \pm 1.0 \mathrm{db} \\ \text { Data processing } & \pm 0.5 \mathrm{db} \\ \text { Acoustical calibration } & \pm 0.1 \mathrm{db} \\ \text { Round-off error } & \pm 0.5 \mathrm{db}\end{array}$

The probable error is therefore,

$$
\begin{aligned}
& \pm \sqrt{0.04+1.0+0.25+0.01+0.25} \\
& \pm \sqrt{1.55}= \pm 1.25 \mathrm{db}
\end{aligned}
$$

This figure is accurate above $0.1 \mathrm{~Hz}$; below that the response of the microphones falls off rapidly.

\section{G. COMPARISON WITH THE NOISE FIELDS OF OTHER JETS}

The noise fields of other jets have been extensively studied. Because of the relatively large size of the duct exit and the high velocity, most of the relevant data is limited to rocket jets. Figure 19 shows the relationships between sound power and mechanfcal power for this and similar studies. The data shown for nuclear rockets are taken from Manhart (2), data for chemical rockets are taken from Cole ${ }^{(10)}$ and others as noted.

The eighth power law of Lighthill (3), which gives such a good correlation for small, subsonic, cold-air jets, does not appear applicable for 


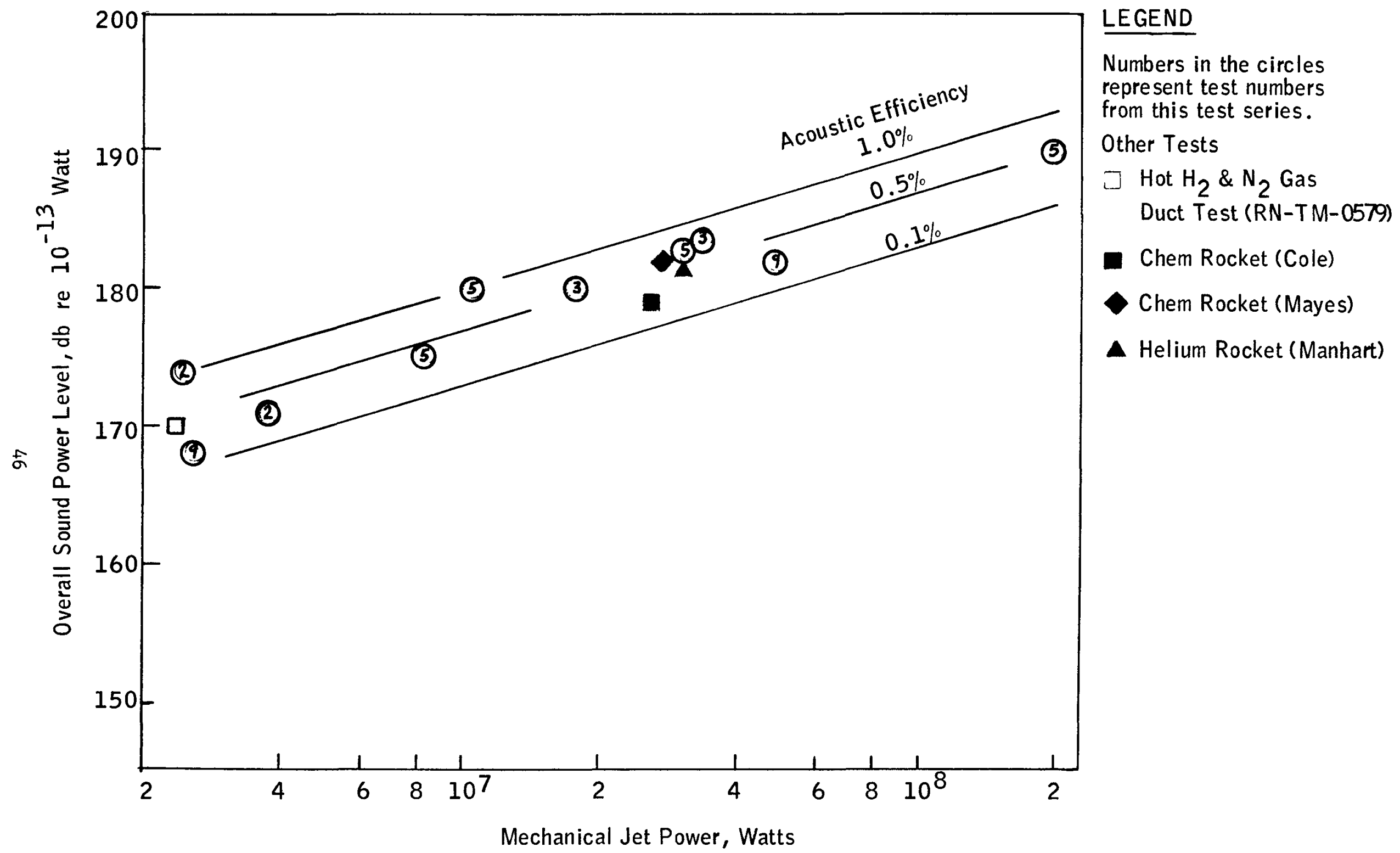

Figure 19 - Relation of Sound Power and Mechanical Power 
large jets with high-velocity gases. The number of important parameters is probably much greater than those of a cold-air jet: gases of radically different molecular weight are mixing, the acoustic velocity in the jet is not the same as in the atmosphere, and the gas does not follow the 45 degree turn of the pipe elbow at the exit but turns only a fraction of that amount, to name only a few effects.

The mechanical power level of the jet when the engine is operating at design is about 400 times that at zero power. Because steam is flowing, regardless of the engine power, at about $130 \mathrm{lb} / \mathrm{sec}$, the ratio is not infinite. The difference in efficiency was only $26 \%$. This indicates a nearly constant efficiency in conversion of mechanical power to sound power over a wide range of thrust power. This trend was demonstrated to extend over a range of jet mechanical power from $10^{5}$ to $10^{8}$ watts. Other investigators have confirmed this trend. 
VI. COMBUSTION STUDIES

The noise that is emitted by a flame is well known to anyone who has witnessed a large forest or petroleum flre. However, the chemical compositions that will sustain combustion must be uniquely determined for each new situation. Additional noise can be expected when oscillatory combustion is present as in the familiar singing flame phenomenon. Available literature was evaluated for application to combustion studies. It appears that the field of combustion noise from flames is large and growing; essentially all of this work, however, is devoted to combustion chambers in some form and is not germane to the free, turbulent, diffusion flames typical of the experiments in this program. In view of the lack of applicable 1iterature, combustion studies were made an important part of this investigation.

Test data were obtained with hydrogen-in-duct effluent ranging from 5 to 87 mol percent. One useful side result of the test series is that predictions regarding the dynamic lower flammability limit of about 22 mol percent were confirmed.

\section{A. CONTRIBUTION OF BURNING TO NOISE}

The overall acoustic conversion efficiencies of the earlier scalemodel tests ${ }^{(1)}$ were calculated by using the equations presented earlier. Typical results are shown below:

ACOUSTIC CONVERSION EFFICIENCY, GAS JETS WITH NO BURNING (Nitrogen Gas with a Small Amount of Hydrogen Gas)

$\begin{array}{lllllll}\text { Test No. } & \text { A10 } & \text { A11 } & \text { A11 } & \text { A12 } & \text { A14 } & \text { A14 } \\ \text { Time, sec } & 32 & 8 & 18 & 12 & 30 & 16 \\ \text { Average Acoustic Conversion Efficiency } \% & 0.39 & 0.36 & 0.31 & 0.33 & 0.46 & 0.47 \\ \text { Duct Gas Temperature }{ }^{\circ} \mathrm{R} & 1547 & 1065 & 1066 & 1058 & 647 & 668 \\ \text { Average efficiency of all tests is 0.39\% } & & & & & & \\ \text { Note: Extracted without change from Reference (1). }\end{array}$


When this average is compared with that of burning hydrogen jets it can be seen that the overall noise of the combusting system is slightly greater than for the nonburning jet for the same mechanical jet power. The contribution of burning to noise was shown to be much more evident in the frequency analysis, and it was concluded that the effect of combustion is additive and is confined to the low frequencles, 100 and $200 \mathrm{~Hz}$ band.

The results of this test series tend to confirm the conclusions presented in the scale-model test report ${ }^{(1)}$. The overall contribution to noise when the mechanical jet power and thermal jet power (based on heating value) are similar is calculable but generally not significant. The contribution is confined to the low frequencies, 50 to $200 \mathrm{~Hz}$ band.

\section{B . OSCILLATORY COMBUSTION}

Oscillatory combustion has been observed in numerous experiments. The first attempt to explain it was by Lord Rayleigh ${ }^{(9)}$. In large-size installations these oscillations can be more than annoying - they can be destructive to equipment. At the present time it is difficult, if not impossible, to design a duct system to assure that oscillatory combustion will not occur. A list of the reasons would include:

1. The exact driving mechanisms are only partially understood.

2. Oscillations can occur in many different combinations.

3. The geometry of any real system is too complicated to model exactly.

4. The mathematics of analysis are primitive.

Because of this the results from each test were analyzed for evidence of oscillatory combustion. The test data (motion-picture film, magnetic tapes, personal observations, etc.) were studied for any indication of oscillatory combustion. No evidence of oscillatory combustion was found. 
VII. COMPARISON OF PREDICTED AND ACTUAL SOUND PRESSURE LEVELS

The objective of this investigation (ETS-1 Modification No. 175) was to modify ETS-1 structures to be capable of withstanding the acoustic loads emanating from the combusting duct exhaust plume. Preliminary estimates of the plume-generated nolse level indicated that walls designed to sustain these acoustic forces would be more than adequate in terms of all other design criteria; acoustics thus became the controlling design factor.

Accordingly, as soon as the preliminary results of the scale-model test program were avallable (Reference 1), these data with pertinent literature information were reviewed by representatives of Paul S. Veneklasen and Associates, LASL, MSFC, and Aerojet.* Because engine full-power testing was considered the most severe mode of operation, a pretest prediction of 154 and $140 \mathrm{db}$ OASPL was made for the centers of the duct-vault inerting wall and the upper heat shield respectively, thus establishing the acoustic design criteria for each wall.

Sound pressure levels at selected times are shown for the tests of interest in Table 6. Restricting discussion to Test 5C, the full-power run, as imposing the highest acoustic loadings, the data show an OASPL of $158.0 \mathrm{db}$ at the center of the duct-vault inerting wall just above the duct exit (Microphone HM 113) and $142.0 \mathrm{db}$ at the center of the upper heat shield (Microphone HM 115). These measured values are 4 and $2 \mathrm{db}$ higher than predicted. The possibllity that this increase could be the result of experimental error, higher-than-anticipated jet-power energy, or near-field energy accentuation was evaluated and found insufficient to account for a discrepancy of this magnitude.

Æon 21 August 1968 
After a review of the pretest estimate method and the test measurements from full-power run (5C), the most likely explanation of this discrepancy lies in an increase of the mechanical-acoustic conversion efficiency beyond that determined in scale-model testing. Whether this is caused by a change in duct effluent composition (hydrogen and nitrogen was used in scale-model flows and hydrogen and steam in the full-scale system) or to a scale-up effect that was not adequately modeled in the pretest-prediction method is open to conjecture. The mechanical conversion efficiency initially estimated from scale-model data was $0.20 \%$. The corresponding value calculated from the four microphone signals for the full-power run, suitably integrated, is $0.50 \%$, a factor of 2.5. The agreement between microphone readings, which is sensitive to application of conventional principles to scaling as well as to estimates for the near field, far field, and wall and directivity effects, is within $\pm 1 \mathrm{db}$ of the initially estimated values. Sound pressure levels were estimated for the inerting wall and upper heat shield by using the pretest model but with a mechanical conversion efficiency of $0.50 \%$. The results are shown in Figure 20. 


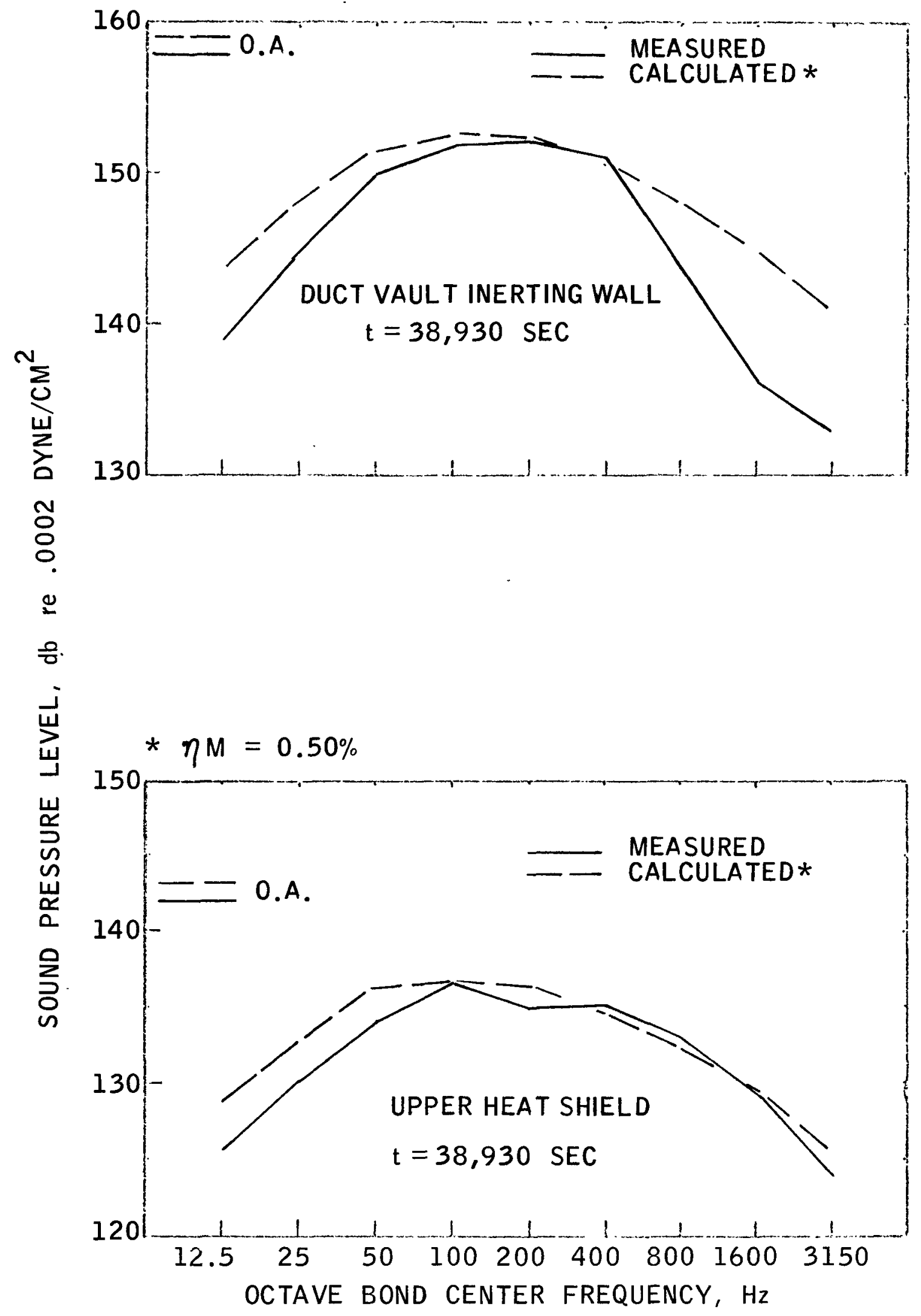

Figure 20 - Comparison, Measured and Predicted Sound Pressures 


\section{RECOMMENDED PREDICTION METHOD}

A major objective of the investigation was to develop an acoustic prediction method suitable for this application (high-energy gas jets, near-sonic gas velocities, both near and far field, and large amounts of free hydrogen in the duct gas). Accordingly, as soon as the preliminary results of the scale-model tests were complete, a preliminary model was developed. As engine test results became avallable, the theory was expanded and improved. The recommended prediction method is described below.

The jet kinetic power is calculated:

$$
\text { WMJET }=0.676 * \text { WDOT * }(\text { VEXIT })^{2} /\left(2 * g_{c}\right)
$$

The jet thermal power is also calculated:

$$
\text { WTHJET }=\text { WDOTF } * \text { HCB }
$$

The overall acoustic power and power level are obtained from a knowledge of the jet kinetic and thermal powers.

$$
\begin{aligned}
& \text { OAPW }=n T H * \text { WTHJET }+n M * \text { WMJET } \\
& \text { OAPWL }=130+10 \log (\text { OAPW })
\end{aligned}
$$

where $\eta \mathrm{TH}$ and $\eta \mathrm{M}$ are estimated from scale model testing or relevant test data.

This completes the calculation of overall power level, the first part of the analysis. The spectral calculation follows:

The Strouhal number is estimated:

$$
\mathrm{NSTR}=\text { FREQ } * \text { DEXIT/VEXIT }
$$


The power-spectrum level is estimated from the data of Refs. 1, 2, 5 or 6 , and the octave-band power level from:

$$
\begin{aligned}
& \text { OBPWL }=\text { OASPL }+ \text { OAPWL }-10 \text { LOG (VEXIT/DEXIT) } \\
& +10 \log (\text { FREQ } * \sqrt{2})
\end{aligned}
$$

The directivity index, near field, and wall effects are estimated from scalemodel data or relevant sources and the octave-band and overall sound pressure level calculated from:

$$
\begin{aligned}
& \text { OBSPL }=\text { OBPWL }-10 \log \left(2 \pi \mathrm{R}^{2}\right)+\text { DINDX }+ \text { DNF + DWALL } \\
& \text { OASPL }=10 \log \sum_{i=1}^{M} \operatorname{Antilog}\left(\frac{\text { OBSPL }}{10}\right)_{i}
\end{aligned}
$$

This method is superior to conventional methods when large amounts of energy are released by combustion as $\mathrm{nM}$ and $\mathrm{nTH}$ can be estimated separately and probably more accurately.

Nomenclature basis is as before, but with the following new symbols:

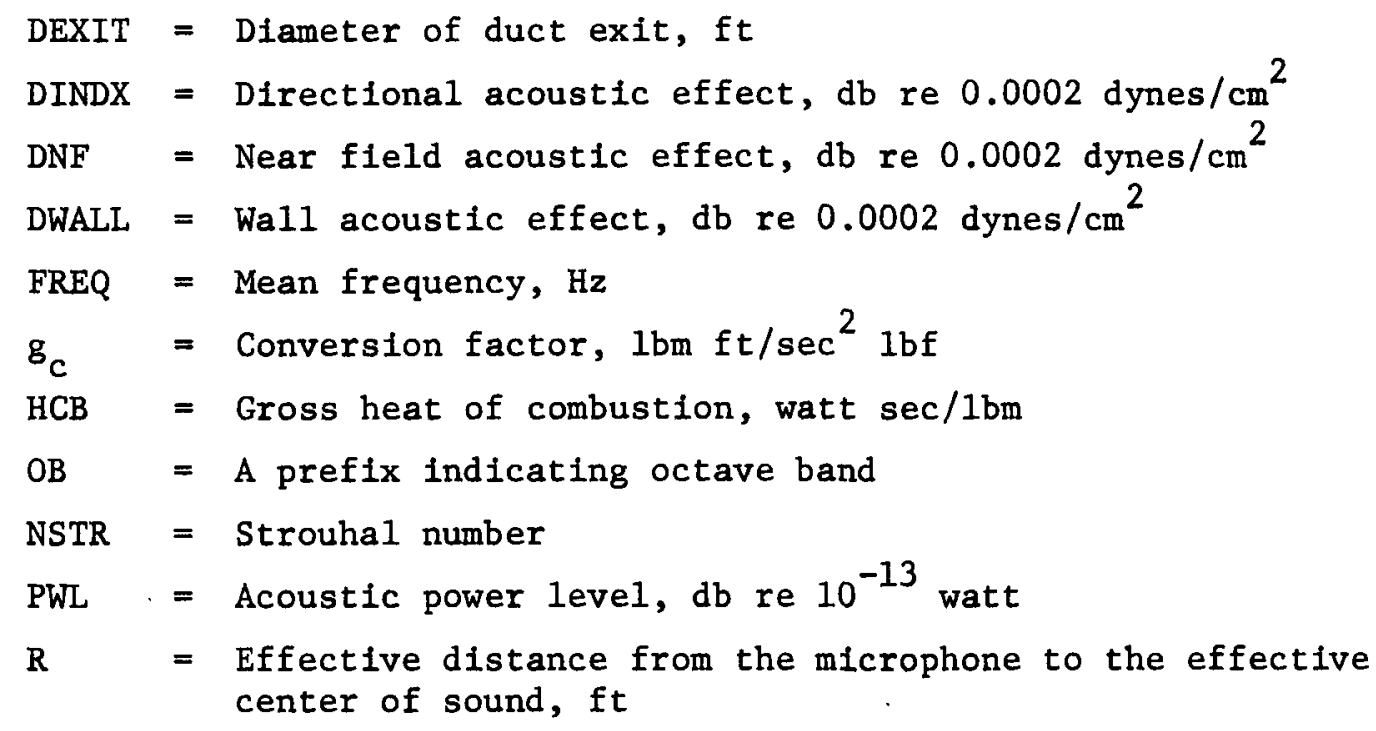


VEXIT = Gas velocity at duct exit, fps

WDOT = Total duct gas flow, pps

WDOTF = Hydrogen duct gas flow, pps 
IX. CONCLUSIONS

An investigation to determine the acoustic characteristics of a $4.33 \mathrm{ft}$ dia hot-gas-jet with mechanical jet power to 190 megawatts exhausting to the atmosphere at an angle of about 40 degrees to the horizontal has been completed. The gas-jet composition was varied, but consisted essentially of mixtures of hydrogen and steam. The characteristics of the sound field generated have been delineated and compared with those of other nuclear rockets, chemical rockets, and cold- and hot-gas jets. Examination of the data shows that the sound field has the following characteristics:

1. The recommended prediction method described herein predicts the noise field resulting from power tests of the $\mathrm{XE}$ nuclear rocket engine in a satisfactory manner. The calculated value of overall sound pressure level is about $1 \mathrm{db}$ higher than the measured value.

2. Based on the thermal mechanical model a $0.31 \%$ mechanical-power-toacoustic-power conversion efficiency and a $0.0023 \%$ thermal-power-to-acousticpower conversion efficlency were obtained from an average of the test data. Based on the mechanical model, the acoustic-power conversion efficiency of about $0.73 \%$ was obtained frcm an average of the test data.

3. Acoustic power was added by the combustion process in the octave bands centered at 50,100 , and $200 \mathrm{~Hz}$. Very little effect was noted at other frequencies.

4. The spectral shape for the jets noise field agrees quite well with that found by overton ${ }^{(6)}$, and the acoustic efficiency with that found by Manhart ${ }^{(2)}$.

5. A predicted dynamic limit of flammability of about 22-mol percent hydrogen for the test conditions and geometry of this program was confirmed. 
6. No evidence of oscillatory combustion was observed in any of the experiments.

7. Examination of the octave-band sound pressure spectra for the full-power jet indicates about $5 \mathrm{db}$ per octave roll-off below the frequency at which the sound pressure is a maximum and a roll-off of about $2.5 \mathrm{db}$ per octave above this frequency.

8. The probable accuracy of the individual measurements is estimated to result in an overall accuracy of $\pm 1.25 \mathrm{db}$ in the sound pressure levels as calculated from the measurements.

9. The simple eight power law of Lighthil1 ${ }^{(2)}$, which gives good results for small, subsonic, cold-air jets is not applicable to large, lowmolecular weight, near sonic, hot-gas jets.

10. The pretest model is satisfactory for prediction of the acoustic field if allowance is made for the effect of steam on the mechanical conversion efficiency. 


\section{REFERENCES}

1. R. S. Fairall "An Acoustical Study of the Noise Field of the Jet from the ETS-1 Scale-Model NES Duct", Aerojet-General Corporation Report RN-TM-0579, Sacramento, California, January 1969.

2. J. Kenneth Manhart, C. M. Ailman, S. R. Lane, and A. H. Marsh, An Acoustical Study of the KIWI B Nuclear Rocket, NASA CR-370, January 1966.

3. M. J. Lighthi11, "Jet Noise," AIAA Journa1, Volume 1, 1507-1517, July 1963.

4. B. Washburn and C. Fenstermacher, "Acoustical Problem Survey and Recommendations," LASL Test CeIl C Memo, February 6, 1968.

5. W. H. Mayes and W. E. Lanford, Near Field and Far Field Noise Surveys of Solid Fuel Rocket Engines, NASA TN D-21, August 1959.

6. J. B. Overton, Methods for Establishing Noise Levels from a Missile Firing and Effects of These Noise Leve1s, NMC-TM-60-33, California, U. S. Navy Missile Center, Pt. Mugu, August 1960.

7. E. Grande, J. B. Large, and A. 0. Anderson, "The Development of Engineering Practice in Jet and Compressor Noise," Paper No. 68-550, AIAA Conference, Cleveland, Ohio, June 1968.

8. Walten L. Howes, Similarity of Far Noise Fields of Jets, NASA TR-T-52, 1960.

9. Lord Rayleigh, The Theory of Sound, Dover Press, N.Y., N.Y., 1945.

10. J. C. Ortega, Acoustic Analysis Relating to ETS-1 Duct Vault Inerting Wa11, Pau1 S. Veneklasen and Associates, Santa Monica, California, December 27, 1968. 
ACKNOWLEDGEMENTS

Messrs. J. R. DaVolio, G. O. Patmor, K. Sato, D. Holzman and M. Kasahara of Aerojet contributed greatly to this study. Dr. Hugo Steiner and Mr. R. Jewel1, Marsha11 Space Flight Center, Mr. B. Washburn, and Dr. C. P. Robinson, Los Alamos Scientific Laboratory, estimated plume acoustic properties and SPL. Messrs. P. S. Veneklasen and J. C. Ortega of Paul S. Veneklasen and Associates assisted in planning the scale-model tests, analyzing the test data, and estimating test stand SPL. Mr. G. K. Sievers, Space Nuclear Propulsion Office-Cleveland, provided direction, guidance, and support for the program. The objectives could not have been accomplished successfully without the support of these men. 